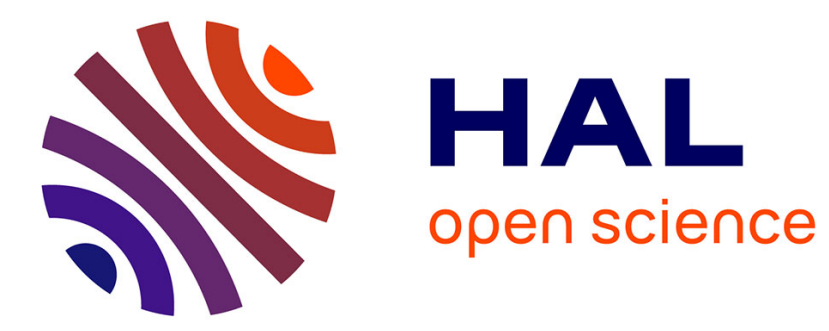

\title{
Modeling the direct and indirect effects of copper on phytoplankton-zooplankton interactions
}

Loïc Prosnier, Michel Loreau, Florence D Hulot

\section{To cite this version:}

Loïc Prosnier, Michel Loreau, Florence D Hulot. Modeling the direct and indirect effects of copper on phytoplankton-zooplankton interactions. Aquatic Toxicology, 2015, 162, pp.73-81. 10.1016/j.aquatox.2015.03.003 . hal-01391100

\section{HAL Id: hal-01391100 https://hal.science/hal-01391100}

Submitted on 2 Nov 2016

HAL is a multi-disciplinary open access archive for the deposit and dissemination of scientific research documents, whether they are published or not. The documents may come from teaching and research institutions in France or abroad, or from public or private research centers.
L'archive ouverte pluridisciplinaire HAL, est destinée au dépôt et à la diffusion de documents scientifiques de niveau recherche, publiés ou non, émanant des établissements d'enseignement et de recherche français ou étrangers, des laboratoires publics ou privés. 


\section{Modeling the direct and indirect effects of copper on phytoplankton-zooplankton interactions}

Loïc Prosnier $^{1 *}$, Michel Loreau ${ }^{2}$, Florence D. Hulot ${ }^{1}$

1. Laboratoire Ecologie, Systématique et Evolution, UMR 8079, Univ. Paris-Sud, Bât. 362, 91405 Orsay cedex, France

2. Centre for Biodiversity Theory and Modelling, Station d'Ecologie Expérimentale du CNRS, 09200 Moulis, France

* Corresponding author. E-mail address: loic.prosnier@ upmc.fr; Phone number: + 331 44273249.

Present address: iEES-Paris, UMR7618, UPMC, 4 place Jussieu 75005 Paris, France. 


\section{Abstract}

Predicting the effects of pollution at the community level is difficult because of the complex impacts of ecosystem dynamics and properties. To predict the effects of copper on a plant-herbivore interaction in a freshwater ecosystem, we built a model that focuses on the interaction between an alga, Scenedesmus sp., and a herbivore, Daphnia sp. The model assumes logistic growth for Scenedesmus and a type II functional response for Daphnia. Internal copper concentrations in Scenedesmus and Daphnia are calculated using a biodynamic model. We include two types of direct effects of copper on Scenedesmus and Daphnia that results from hormesis: a deficiency effect at low concentration and a toxic effect at high concentration. We perform a numerical analysis to predict the combined effects of copper and nutrient enrichment on the Scenedesmus-Daphnia interaction. Results show three types of outcomes depending on copper concentration. First, low $\left(4 \mu \mathrm{g} \cdot \mathrm{L}^{-1}\right)$ and high (50 $\left.\mu \mathrm{g} . \mathrm{L}^{-1}\right)$ copper concentrations cause deficiency and toxicity, respectively, leading to the extinction of all populations; for less extreme concentrations (between 4 and $5 \mu \mathrm{g} . \mathrm{L}^{-1}$ and between 16.5 and $50 \mu \mathrm{g} . \mathrm{L}^{-1}$ ), only the consumer population becomes extinct. The two populations survive with intermediate concentrations. Second, when population dynamics present oscillations, copper has a stabilizing effect and reduces or suppresses oscillations. Third, copper, on account of its stabilizing effect, opposes the destabilizing effect of nutrient enrichment. Our model shows that (1) Daphnia is affected by copper at lower concentrations when community interactions are taken into account than when analyzed alone, and (2) counterintuitive effects may arise from the interaction between copper pollution and nutrient enrichment. Our model also suggests that single-value parameters such as NOEC and LOEC, which do not take community interactions into account to characterize pollutants effects, are unable to determine pollutants effects in complex ecosystems. More generally, our model underscores the importance of ecosystem-scale studies to predict the effects of pollutants. 


\section{Introduction}

Laboratory tests used to assess the toxicology of chemicals are mostly based on single species tests. Typically, the effects of chemicals are assessed with a model species, and several parameters describing the toxicological effects for an external concentration are calculated (NOEC, $\mathrm{LC}_{50}, \mathrm{LD}_{50}$, etc.). These parameters reflect the toxicological effects of a chemical on a species in the laboratory; such an organism-centered approach (Villeneuve and Garcia-Reyero, 2011) considers only the direct effects (Strauss, 1991). However, estimating toxicological effects on an ecosystem is more challenging because of the complex impacts of ecosystem dynamics and properties (Fleeger et al., 2003). For instance, Lampert et al. (1989) tested the effects of the herbicide atrazine on some aquatic systems. Laboratory tests on Daphnia showed an effect with an effective concentration of $2 \mathrm{mg} . \mathrm{L}^{-1}$, while tests on a food chain system with Daphnia and algae showed a significant reduction in Daphnia population growth at $0.1 \mathrm{mg} \cdot \mathrm{L}^{-1}$. A third test conducted in enclosure experiments with natural communities showed responses to atrazine concentrations between 0.1 and $1 \mu \mathrm{g} . \mathrm{L}^{-1}$. These experiments show that indirect effects can be greater than direct effects (Lampert et al., 1989) and that standard laboratory tests do not reveal the indirect effects of pollution at the community level. In addition to indirect effects, studying the effects of pollutants on ecosystems requires the consideration of the organisms' internal concentration, which varies with trophic level, as well as the pollution from multiple contaminants. As a consequence, predicting the effects of pollution at the community level is a complex issue. Therefore, studying pollutant effects with ecosystem-centered approaches is the focus of the new paradigm of the Ecological Risk Assessment (Villeneuve and Garcia-Reyero, 2011).

Mathematical modeling has already proved a useful tool to help predict the effects of a pollutant at the population (Manyin et al., 2008) and ecosystem (Traas et al., 1998; Trudel et al., 2001; Van den Brink et al., 2006) levels in a few cases. Although food web models have 
been applied to the study of persistent organic pollutants such as PCBs, introducing more ecological thinking into the analyses of contaminant effects still represents a major challenge (Campfens et al., 1997; Scharler et al., 2005).

In this article, we build a model designed to predict the effects of copper on an important plant-herbivore interaction in freshwater ecosystems. As a receptor of urban wastewater, industrial and mine effluents, agricultural runoff, and atmospheric pollution, aquatic ecosystems are prone to copper pollution (Jørgensen et al., 2010; Nriagu, 1979). Copper is an essential element of life (Mertz, 1981) as it enters the composition of numerous enzymes. A low internal concentration may induce deficiency effects (Bossuyt and Janssen, 2003). However, single-species tests in the laboratory showed that copper is highly toxic at high concentrations (Clements et al., 1992). Copper has negative impacts on primary producers, microorganisms, invertebrates, fish, and amphibians (ATSDR, 1990; WHO, 1998).

In this article, we examine the copper effects on the interaction between algae and Daphnia sp. for several reasons. First, this interaction plays a key role in the dynamics of many freshwater ecosystems (McCauley et al., 1987; McCauley et al., 1988) and it is commonly used as a model system in ecology and ecotoxicology. Algae and Daphnia are frequently used in toxicology tests on isolated populations (Reynolds, 2011) as well as in standard ecotoxicological tests, for instance, for water quality monitoring. Although our model focuses on a specific prey-predator interaction, it is representative of communities with strong trophic interactions (Berlow et al., 1999, 2004), as is generally the case in freshwater ecosystems (Shurin et al., 2006).

Second, various direct effects of copper on algae and Daphnia sp. have been described, which allows us to accurately describe its effects on this particular plant-herbivore interaction.

The direct effects of copper on algae include the inhibition of photosynthesis (Havens, 1994), inhibition of growth (Fargasova et al., 1999; Fathi et al., 2000; Yan et al., 2002), 
decreased concentrations of glucides, proteins, amino-acids (Fathi et al., 2000), and chlorophyll (Fargasova et al., 1999) in algal cells, and decreased alkaline phosphatase activity (Fathi et al., 2000). The direct effects of copper on Daphnia sp. life-history traits include a decrease in fecundity, survival, body length, weight, and carbon uptake, as well as a delay in maturation (Baird et al., 1991; Ingersoll et al., 1982; Knops et al., 2001; Koivisto et al., 1992; Winner et al., 1976). Moreover, some behavioral responses of Daphnia to copper are known: their mobility decreases (Clement et al., 2004), while their swimming velocity, filtration rate, and ingestion rate are optimal for an intermediate copper range (Ferrando et al., 1993; Untersteiner et al., 2003). These behavioral modifications may indirectly affect ecological interactions. For instance, the effect of copper on Daphnia's mobility (Clement et al., 2004; Gutierrez et al., 2012; Sullivan et al., 1983) in turn affects its foraging behavior and ability to escape predators, and, ultimately, its prey and predator populations. Concerning Scenedesmus' behavior, copper reduces the colonies that they form in response to Daphnia's predation (Lürling and Van Donk, 2000; Peña-Castro et al., 2004; Van Holthoon et al., 2003; Wu et al., 2013).

The study of copper effects is complicated by copper speciation and environmental factors. The response of each species' life-history trait-for instance, growth rate, predation, and mortality-varies greatly due to copper speciation (Van Veen et al., 2002). For example, the $\mathrm{EC}_{50}$ for Daphnia sp. can range from simple to twentyfold (Jørgensen et al., 2010). In addition, many environmental factors such as $\mathrm{pH}$ and $\mathrm{CO}_{3}{ }^{2-}, \mathrm{Ca}^{2+}, \mathrm{Mg}^{+}, \mathrm{Na}^{+}, \mathrm{K}^{+}, \mathrm{Cl}^{-}$, and $\mathrm{SO}_{4}{ }^{2-}$ concentrations also modify responses to copper concentration (De Schamphelaere and Janssen, 2002). A few toxicity values can be determined for species-pollutant couples with the Biotic Ligand Model. This model allows the $\mathrm{LD}_{50}$ and $\mathrm{EC}_{50}$ to be determined for some species and pollutants as a function of variable environmental parameters (see Paquin et al. (2002) for an overview and De Schamphelaere and Janssen (2002) for an example). 
In this study, we use our model to analyze the effects of copper pollution on the Scenedesmus-Daphnia interaction. Nutrient enrichment has major destabilizing effects on prey-predator interactions, known as the paradox of enrichment (Rosenzweig, 1971). As freshwater ecosystems are often subject to nutrient enrichment, which is a major perturbation in aquatic ecosystems (Dudgeon et al., 2006; Sala et al., 2000), we also study the interaction between copper pollution and eutrophication.

\section{Methods}

\subsection{Modeling freshwater ecosystems and copper effects}

We consider a simple freshwater ecosystem consisting of two compartments, phytoplankton and zooplankton, with the genera Scenedesmus and Daphnia chosen as model organisms for these compartments. These genera include many species, but since the associated species have very similar life-history traits (McCauley et al., 1988), we do not distinguish them in our study. Moreover, all Scenedesmus species are approximately the same size, which is the main criterion for describing Daphnia's size-based predation (Briand et al., 1978; Burns, 1968; McCauley et al., 1988; Porter, 1973).

In freshwater environments, various phenomena of copper speciation have been described (Nomkoko et al., 2003; Van Veen et al., 2002). Moreover, the amount of bioavailable copper depends on many environmental parameters (Town et al., 2000). Among the various chemical forms toxic to freshwater organisms, it is widely acknowledged that copper toxicity is directly related to the concentration of free and bioavailable $\mathrm{Cu}^{2+}$ in water (Nomkoko et al., 2003; Van Veen et al., 2002). Therefore, we focus on this form in our study, referring to its concentration as copper concentration in water. Copper impacts on organisms may be either direct or indirect. Direct effects are due to copper bioconcentration in organisms through direct absorption (through skin or gills, or by drinking contaminated water) as well as its progressive 
accumulation in tissues, as copper excretion is weaker than copper absorption (ATSDR, 1990; WHO, 1998). Indirect effects occur through modifications to the densities and dynamics caused by the pollutant on the life-history traits of the concerned and related species.

\subsection{Model}

The model development follows several steps. We first model the Scenedesmus-Daphnia interaction without copper pollution. Next, we calculate the internal concentration of copper and analyze its effects on each species. Finally, we include its effects on model parameters to describe the Scenedesmus-Daphnia interaction in the presence of copper pollution. Our analysis relies on a classical community model that includes two variables, Scenedesmus and Daphnia densities.

\subsubsection{Scenedesmus-Daphnia interaction}

In a constant environment, Scenedesmus dynamics is assumed to be logistic (McCauley et al., 1988). The functional response of Daphnia is well described by a type II functional response (Demott, 1982; Porter et al., 1982). Therefore, the Rosenzweig-MacArthur model (Rosenzweig and MacArthur, 1963) based on logistic growth for Scenedesmus and a type II functional response for Daphnia realistically describes the Scenedesmus-Daphnia interaction (McCauley et al., 2008; Murdoch et al., 1998; Nisbet et al., 1991):

$\left\{\begin{array}{l}\frac{d S}{d t}=r \cdot S \cdot\left(1-\frac{S}{K}\right)-\frac{I_{\max x} \cdot D \cdot D}{S+h} \\ \frac{d D}{d t}=\left(e \cdot \frac{I_{\max } \cdot S}{S+h}-m\right) \cdot D\end{array}\right.$

where $S$ and $D$ are Scenedesmus and Daphnia densities $\left(\mathrm{mgC}^{-1} \mathrm{~L}^{-1}\right)$, respectively, $r$ Scenedesmus intrinsic rate of natural increase $\left(\mathrm{d}^{-1}\right), K$ Scenedesmus carrying capacity $\left(\mathrm{mgC} . \mathrm{L}^{-1}\right), I_{\max }$ the maximum intake rate of the Daphnia $\left(\mathrm{d}^{-1}\right), h$ the half-saturation constant of 
Daphnia (mgC/L), $e$ the Daphnia conversion efficiency, and $m$ Daphnia mortality rate $\left(\mathrm{d}^{-1}\right)$. Parameter values derived from the literature are given in Table 1.

\subsubsection{Internal copper concentration of organisms}

Previous ecotoxicological studies report the toxicity of copper for a given external concentration and a short duration, usually ranging from 24 to 72 hours and rarely up to one week. Unfortunately, the trophic position or the effect of biomagnification for the species under examination is rarely specified. We hypothesize here that the variation of the effects can be caused by the copper absorption and exposure durations. As a consequence, taking into account the internal concentration allows us to use these toxicity data for modeling the longterm dynamics of the system. Implicitly, internal concentration reflects the toxicity and neglects the absorption duration. However, this internal concentration should take the species trophic position into account. Consequently, we determine the internal concentration $\left(\mathrm{Cu}_{\text {int }}\right)$ as a function of the external concentration for each population. This can be derived with the following biodynamic model (Luoma and Rainbow, 2005):

$C u_{\text {int }}=\left(\left(C u \times k_{u}\right)+\left(C u_{F} \times A E \times I R\right)\right) / k_{e}$

Where $C u$ is the external concentration $\left(\mu \mathrm{g} \cdot \mathrm{L}^{-1}\right), k_{u}$ the constant uptake rate $\left(\mathrm{L} \mathrm{g}^{-1} \cdot \mathrm{d}^{-1}\right), C u_{F}$ the copper concentration in food, $A E$ the assimilation efficiency $(\%), I R$ the ingestion rate $\left(\mathrm{g} \cdot \mathrm{g}^{-1} \cdot \mathrm{d}^{-1}\right)$, and $\mathrm{k}_{\mathrm{e}}$ the constant loss rate $\left(\mathrm{d}^{-1}\right)$.

Equation (2) allows us to calculate the internal concentration as a function of the external concentration, direct absorption $\left(C u \times k_{u}\right)$, and food absorption $\left(C u_{F} \times A E \times I R\right)$. It includes bioconcentration and biomagnification effects, and thus, the species' trophic level.

This equation shows a linear relation between copper external and internal concentrations. However, direct absorption is modified by ionic competition between copper ions (Lebrun et al., 2012). The uptake constant is modified as follows: 


$$
k_{u}=\frac{k_{m}}{k_{c}+C u}
$$

Where $k_{m}$ is the maximal intake rate $\left(\mu \mathrm{g} \cdot \mathrm{g}^{-1} \cdot \mathrm{d}^{-1}\right)$ and $k_{c}$ the half-saturation constant $\left(\mu \mathrm{g} \cdot \mathrm{d}^{-1}\right)$.

The species' internal concentration is thus:

$$
C u_{i n t(C u)}=\left(\left(\frac{k_{m}}{k_{c}+C u} \times C u\right)+\left(A E \times I R \times C u_{F}\right)\right) / k_{e}
$$

This equation is simplified for the algal copper concentration, where only direct absorption occurs.

Consequently, the internal copper concentrations for Scenedesmus $\left(\mathrm{C}_{\mathrm{S}}\right)$ and Daphnia $\left(\mathrm{C}_{\mathrm{D}}\right)$ as a function of external concentration $(\mathrm{Cu})$ are as follows:

$$
\begin{aligned}
& C_{S(C u)}=\left(\frac{C u \cdot k_{m} S}{C u+k_{c S}}\right) \cdot \frac{1}{k_{e S}} \\
& C_{D(C u)}=\left(\frac{C u \cdot k_{m D}}{C u+k_{C D}}+e \cdot \frac{I_{m a x} \cdot S}{S+h} \cdot C_{S}\right) \cdot \frac{1}{k_{e D}}
\end{aligned}
$$

Where $k_{m S}$ and $k_{m D}$ are the maximal ingestion rates $\left(\mu \mathrm{g} \cdot \mathrm{g}^{-1} \cdot \mathrm{d}^{-1}\right)$ of Scenedesmus and Daphnia, respectively, $k_{c S}$ and $k_{c D}$ their half-saturation constants $\left(\mu \mathrm{g} . \mathrm{L}^{-1}\right)$, and $k_{e S}$ and $k_{e D}$ their constant loss rates $\left(\mathrm{d}^{-1}\right)$.

\subsubsection{Effects of copper on organisms}

It is common to represent copper dose-response relationships by a sigmoid curve that captures only the effect of copper as a pollutant at high concentration. Yet copper is also an essential trace element with a hormetic effect; in other words, a small quantity of copper is vital. Consequently, an asymmetric double sigmoid curve (Figure 1) with a plateau for the optimal range better captures the various effects of copper on organisms. 


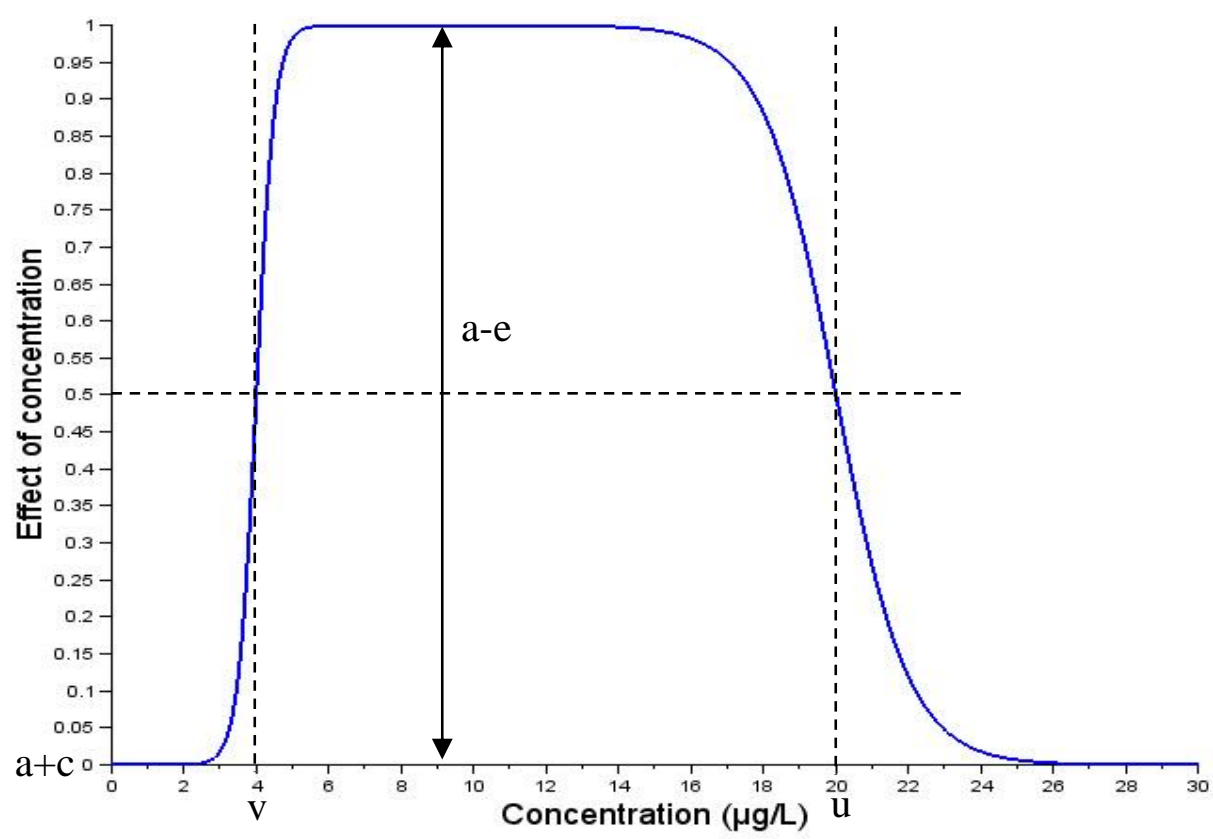

Figure 1: Effect of copper on a given parameter as a function of its concentration in $\mu \mathrm{g} / \mathrm{L}$. The effect is null when equal to 1 . a-e: amplitude of the effect; $a+c=$ minimal value of the effect; $v$ and $u$ : copper concentration for an effect at 0.5 .

The following equation is an asymmetric double sigmoid function with two thresholds, deficiency and toxicity:

$$
\begin{aligned}
C u_{x}= & (a+c)-\frac{1}{2} \times(a-e) \times \tanh \left(d\left(C_{x(C u)}-C_{x(v)}\right)\right)+\frac{1}{2} \times(a-c) \times \\
& \tanh \left(b\left(C_{x(C u)}-C_{x(C u)}\right)\right)
\end{aligned}
$$

Where $C u_{x}$ is the effect of copper on parameter $x,(a+c)$ the minimal value of the effect, $(a$ $e$ ) the amplitude of the effect, $v$ the lower $\mathrm{EC}_{50}$ (deficiency) and $u$ the higher $\mathrm{EC}_{50}$ (toxicity), and $d$ and $b$ the lower and higher slopes of the curve, respectively (see below for explanations). Effects are captured in equation 1 where parameter $x$ is weighted by $C u_{x}$, that is, $x . C u_{x}$.

The effect of copper on Scenedesmus growth rate, $r$, is first negative at low concentrations, then positive with an optimal growth rate at intermediate concentrations, and finally negative again at high copper concentrations. Therefore, the copper effect, $C u_{r}$, ranges from -1 to 1 . Thus, $(\mathrm{a}+\mathrm{c})=-1$ and $(\mathrm{a}-\mathrm{e})=-2$, so $\mathrm{a}=-1.5$ and $\mathrm{c}=\mathrm{e}=0.5$. 
We obtain from (7):

$C u_{r}=-1+\tanh \left(d_{r}\left(C_{S(C u)}-C_{S\left(v_{r}\right)}\right)\right)-\tanh \left(b_{r}\left(C_{S(C u)}-C_{S\left(u_{r}\right)}\right)\right)$

Modeling the effects of copper on Daphnia is more challenging as the pollutant effects on the parameters used in the model are not those tested in laboratory experiments (i.e., functional response and conversion efficiency versus growth and mortality rates). Copper effects on the mortality rate are well documented but, to our knowledge, there are no experiments on the effects of copper on Daphnia's functional response and conversion efficiency. Copper effects on Daphnia velocity were previously reported (Gutierrez et al., 2012; Sullivan et al., 1983; Untersteiner et al., 2003). As velocity is an advantage for a mobile predator (Gerritsen and Strickler, 1977) like Daphnia, these results show that copper affects predation. To capture the effects of copper on the consumer's population growth as described in equation (7), we weight Daphnia's growth rate (i.e., the product of its conversion efficiency and functional response) with a copper parameter.

As a consequence, the effect of copper on predation, $C u_{p}$, ranges between 1 and 0 , that is, between no effect on predation at intermediate concentrations and total inhibition of predation at low and high concentrations. Thus, $(a+c)=0$ and $(a-e)=-1$, so $a=-0.5$ and $c=e=0.5$.

We thus obtain from (7):

$$
C u_{p}=\frac{1}{2} \tanh \left(d_{p}\left(C_{D(C u)}-C_{D\left(v_{d}\right)}\right)\right)-\frac{1}{2} \tanh \left(b_{p}\left(C_{D(C u)}-C_{D\left(u_{p}\right)}\right)\right)
$$

Because there is no hormetic effect of copper on Daphnia mortality but only a negative effect, we model a linear effect on this parameter as follows:

$$
C u_{m}=1+p_{m} \cdot C_{D(C u)}
$$

where $p_{m}$ is a copper response coefficient.

Finally, introducing the copper effects captured in equations (8), (9) and (10) into model (1) leads to the following equations: 


$$
\left\{\begin{array}{l}
\frac{d S}{d t}=r \cdot C u_{r} \cdot S \cdot\left(1-\frac{S}{K}\right)-\frac{I_{\max } \cdot S \cdot D}{S+h} \cdot C u_{p} \\
\frac{d D}{d t}=\left(e \cdot C u_{p} \cdot \frac{I_{\max } \cdot S}{S+h}-m \cdot C u_{m}\right) \cdot D
\end{array}\right.
$$

\subsubsection{Model dynamics with copper effects and nutrient enrichment}

Nutrient enrichment can destabilize prey-predator interactions by changing the equilibrium point from stable to unstable (Appendix A). This effect is known as the paradox of enrichment (Rosenzweig, 1971). Nutrient enrichment and copper pollution might interact and the effects of their interaction might be unpredictable, that is, antagonistic or synergetic. To address this issue, we conducted computer simulations of the Scenedesmus-Daphnia system where we varied the algal carrying capacity $(K)$ to simulate nutrient enrichment and copper concentration in water $(\mathrm{Cu})$.

\subsection{Parameter values and sensitivity analysis}

We parameterized our model with the parameter values provided in Table 1. Some of these values may be found in the literature, while others may not; we therefore gave them arbitrary values.

We then performed a sensitivity analysis by running the model with a $10 \%$ increase or decrease in the value of each parameter for different copper concentrations and algal carrying capacities. 
Table 1: Value of model parameters used for numerical analyses (NS: no source); see text for explanations.

\begin{tabular}{|c|c|c|c|c|}
\hline \multirow[t]{2}{*}{ Parameter } & Description & \multicolumn{2}{|c|}{ Value } & \multirow[t]{2}{*}{ Sources } \\
\hline & \multicolumn{3}{|c|}{$\begin{array}{l}\text { Populations' dynamics } \\
\end{array}$} & \\
\hline $\mathrm{r}$ & Scenedesmus intrinsic rate of natural increase & 1.2 & $d^{-1}$ & Rinke and Vijverberg, 2005 \\
\hline K & Range of Scenedesmus carrying capacity & $0.1-5$ & $\operatorname{mgC} . \mathrm{L}^{-1}$ & Murdoch et al., 1998 \\
\hline $\operatorname{Imax}$ & Maximum intake rate of the Daphnia & 1.8 & & Rinke and Vijverberg, 2005 \\
\hline h & Half-saturation constant of Daphnia & 0.164 & $\mathrm{mgC} . \mathrm{L}^{-1}$ & Murdoch et al., 1998 \\
\hline $\mathrm{e}$ & Daphnia conversion efficiency & 0.6 & - & Rinke and Vijverberg, 2005 \\
\hline $\mathrm{m}$ & Daphnia mortality rate & 0.35 & $\mathrm{~d}^{-1}$ & Rinke and Vijverberg, 2005 \\
\hline \multicolumn{5}{|c|}{ Copper - Internal concentration } \\
\hline $\mathrm{Cu}$ & Range of external copper concentration & $0-100$ & $\mu \mathrm{g} . \mathrm{L}^{-1}$ & Bossuyt and Janssen, 2003 \\
\hline $\mathrm{kmS}$ & Scenedesmus maximal intake rate & 20 & $\mu g \cdot g^{-1} \cdot d^{-1}$ & NS \\
\hline $\mathrm{kmD}$ & Daphnia maximal intake rate & 15 & $\mu g \cdot g^{-1} \cdot d^{-1}$ & Lebrun et al., 2012 \\
\hline $\mathrm{kcS}$ & Scenedesmus half-saturation constant & 6 & $\mu \mathrm{g} . \mathrm{L}^{-1}$ & NS \\
\hline $\mathrm{kcD}$ & Daphnia half-saturation constant & 7 & $\mu \mathrm{g} . \mathrm{L}^{-1}$ & NS \\
\hline keS & Scenedesmus constant loss rate & 1 & $\mu \mathrm{g} \cdot \mathrm{d}^{-1}$ & NS \\
\hline $\mathrm{keD}$ & Daphnia constant loss rate & 1 & $\mu \mathrm{g} . \mathrm{d}^{-1}$ & Lebrun et al., 2012 \\
\hline \multicolumn{5}{|c|}{ Copper - Effects } \\
\hline $\mathrm{vr}$ & Scenedesmus growth's deficiency EC50 & 4 & $\mu \mathrm{g} . \mathrm{L}^{-1}$ & Sandmann and Böger, 1980 \\
\hline ur & Scenedesmus growth's toxicity EC50 & 50 & $\mu \mathrm{g} . \mathrm{L}^{-1}$ & Yan et al., 2002 \\
\hline $\mathrm{dr}$ & Copper effect on Scenedesmus growth & 5 & - & NS \\
\hline br & Copper effect on Scenedesmus growth & 2 & - & NS \\
\hline $\mathrm{vp}$ & Daphnia predation's deficiency EC50 & 5 & $\mu \mathrm{g} . \mathrm{L}^{-1}$ & Bossuyt and Janssen, 2003 \\
\hline up & Daphnia predation's toxicity EC50 & 16.8 & $\mu \mathrm{g} . \mathrm{L}^{-1}$ & Knops et al. 2001 \\
\hline $\mathrm{dp}$ & Copper effect on Daphnia predation & 5 & - & NS \\
\hline bp & Copper effect on Daphnia predation & 1 & - & NS \\
\hline LD50-Daphnia & Daphnia LD50 & 30 & $\mu \mathrm{g} . \mathrm{L}^{-1}$ & Untersteiner et al., 2003 \\
\hline pm & Copper response coefficient for Daphnia mortality & 0.021 & g. $\mu \mathrm{g}^{-1}$ & (deduced from $\mathrm{LD}_{50}$-Daphnia) \\
\hline
\end{tabular}

\section{Results}

\subsection{Effects of copper on Scenedesmus and Daphnia populations}

Depending on the copper concentration, the dynamics of Scenedesmus and Daphnia were stable, cyclic, or showed population extinction (Figure 2). For low $\left(6.5 \mu \mathrm{g} \mathrm{Cu} . \mathrm{L}^{-1}\right.$ ) and medium (13 $\mu \mathrm{g} \mathrm{Cu}$. $\left.\mathrm{L}^{-1}\right)$ copper concentrations, both populations coexist with either oscillations or stable densities. With increasing concentrations of copper $\left(16 \mu \mathrm{g} \mathrm{Cu} . \mathrm{L}^{-1}\right)$, the Daphnia population becomes extinct and for a copper concentration exceeding $50 \mu \mathrm{g} \mathrm{Cu} . \mathrm{L}^{-1}$, the algal population also becomes extinct (Figure 2).

Figure 3 summarizes the dynamics observed for copper concentrations ranging from 0 to $60 \mu \mathrm{g} . \mathrm{L}^{-1}$. For a copper concentration below $4 \mu \mathrm{g} . \mathrm{L}^{-1}$, neither Scenedesmus nor Daphnia population persists because of copper deficiency. For a copper concentration between 4 and $5.2 \mu \mathrm{g} \mathrm{Cu} . \mathrm{L}^{-1}$, only the algal population can grow. For a copper concentration between 5.2 


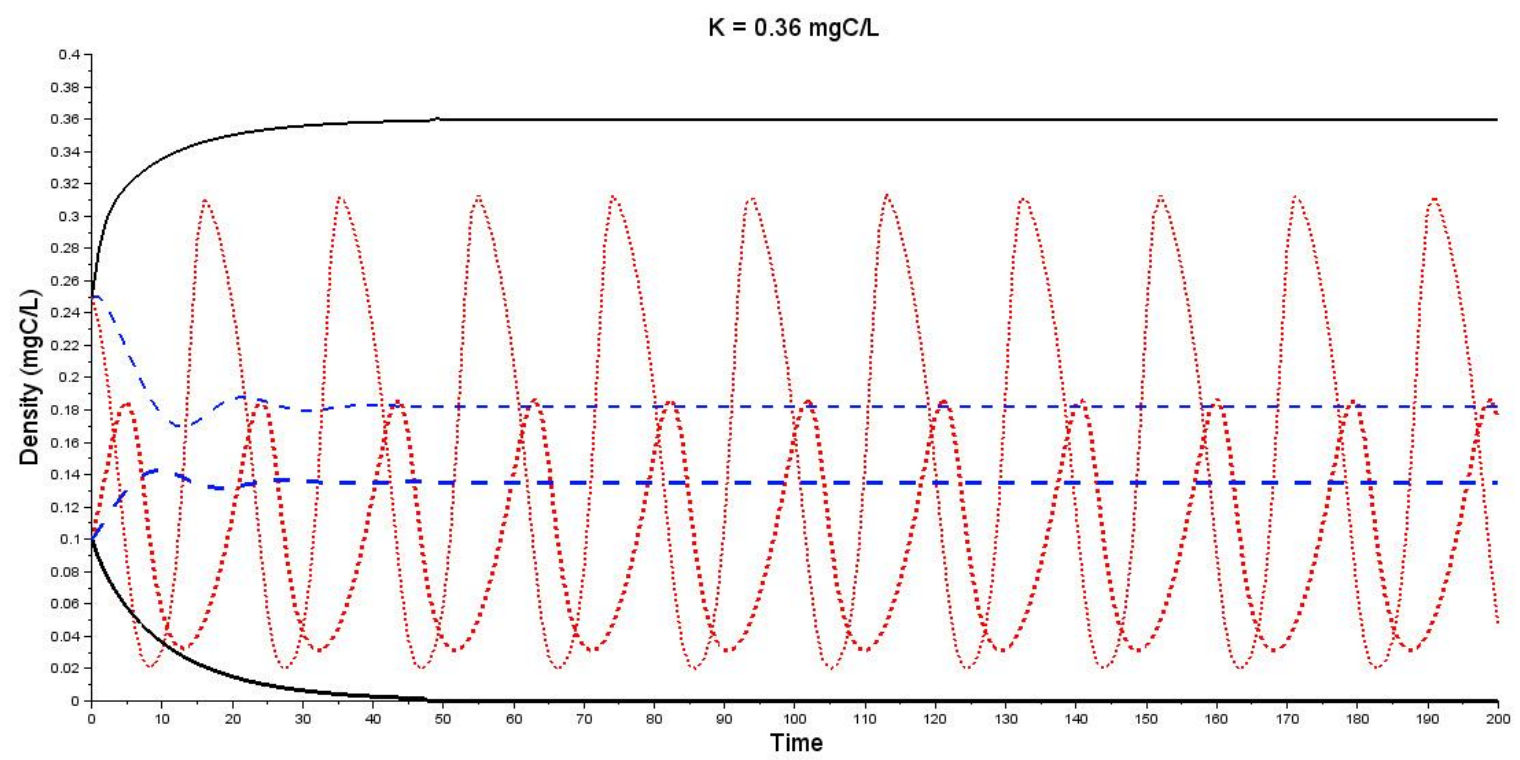

Figure 2: Scenedesmus (thin lines) and Daphnia (bold lines) dynamics for three copper concentrations: 6.5 (dotted lines), 13 (dashes), and 16 (solid lines) $\mu \mathrm{g} \mathrm{Cu/L}$. The dynamics where both populations become extinct is not shown (copper concentration > $50 \mu \mathrm{g} \mathrm{Cu} . \mathrm{L}^{-1}$ ). The carrying capacity is set to $0.36 \mathrm{mgC} / \mathrm{L}$.

and $15 \mu \mathrm{g} \cdot \mathrm{L}^{-1}$, the two populations coexist, first with oscillations and then, beyond 11.8 $\mu \mathrm{g} . \mathrm{L}^{-1}$, with stable densities. For a concentration exceeding $15 \mu \mathrm{g} \mathrm{Cu} . \mathrm{L}^{-1}$, the Daphnia population becomes extinct because of toxicity and for a concentration above $50 \mu \mathrm{g} \mathrm{Cu} . \mathrm{L}^{-1}$, the Scenedesmus population also becomes extinct for the same reason. In short, with increasing copper concentrations, we observe a gradual change from no population to oscillations, stable coexistence, and finally extinction.

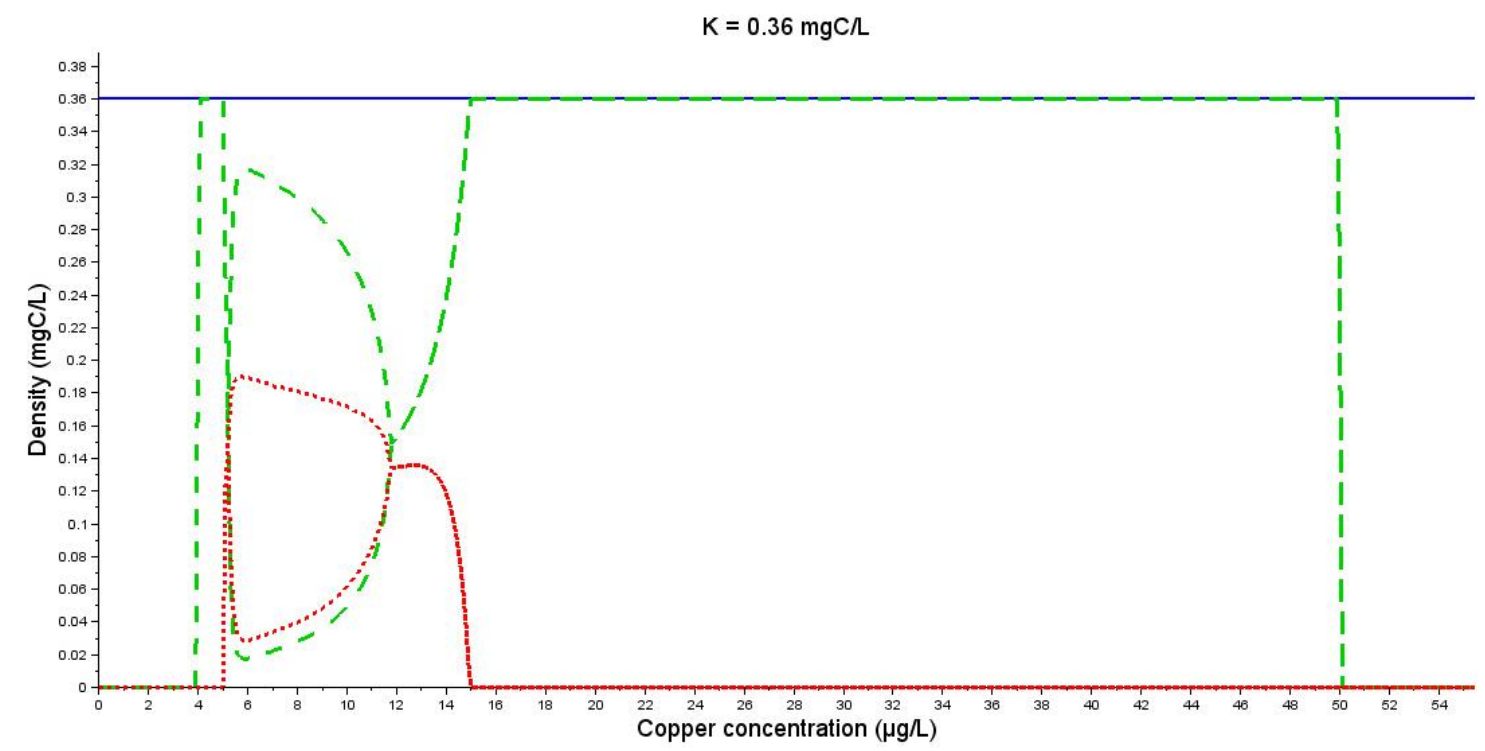

Figure 3: Scenedesmus (dashes) and Daphnia (dotted lines) equilibrium values for copper concentrations ranging between 0 and $55 \mu \mathrm{g} \mathrm{Cu} / \mathrm{L}$. Solid line: carrying capacity. The two lines per population between 5.2 and $11.8 \mu \mathrm{g}$ $\mathrm{Cu} / \mathrm{L}$ show the oscillations' minima and maxima. 


\subsection{Effects of copper and nutrient enrichment on Scenedesmus-Daphnia interaction}

The results summarized in Figure 4 show that copper pollution and nutrient enrichment have antagonistic effects and that copper pollution partially compensates the destabilizing effect of nutrient enrichment. The range of copper concentration that ensures the stable coexistence of Scenedesmus and Daphnia decreases as nutrient enrichment increases.

We distinguish eight outcomes of the model depending on copper concentration and algal carrying capacity (Figure 4). In four of them, the two populations become extinct. For $\mathrm{Cu}<4 \mu \mathrm{g} . \mathrm{L}^{-1}$ and $\mathrm{Cu}>50 \mu \mathrm{g} . \mathrm{L}^{-1}$, Scenedesmus and Daphnia populations become extinct because of copper deficiency and toxicity, respectively (Figure 4, area 1). In the optimal range of copper concentration for Scenedesmus and Daphnia, both populations become extinct because of either a low carrying capacity (below $0.169 \mathrm{mgC} . \mathrm{L}^{-1}$ ) that is not a rich enough medium to support the populations or a high carrying capacity (above $0.428 \mathrm{mgC} . \mathrm{L}^{-1}$ ) that is rich medium inducing a strong destabilization and the collapse of the system (Figure 4, area 2). For low and high copper concentrations (Figure 4, area 3), there are two regions where Daphnia is either deficient or poisoned by copper; Scenedesmus alone persists and reaches its carrying capacity. Finally, for a copper concentration between 5 and $15 \mu \mathrm{gCu} . \mathrm{L}^{-1}$ and a carrying capacity between 0.166 and $0.43-0.5 \mathrm{mgC} . \mathrm{L}^{-1}$ (expanding over a narrow range of carrying capacity up to $8 \mathrm{mgC}^{-1}$ ), the two populations coexist (Figure 4a, area 4). When $K<0.28 \mathrm{mgC.L}{ }^{-1}$ the system is stable (Figure 4b, area 5). However, beyond this value, there are oscillatory dynamics (Figure $4 \mathrm{~b}$, area 6 ).

Figure 4 shows the toxicological values used for model parametrization, i.e. the Scenedesmus and Daphnia $\mathrm{LD}_{50}$. These values are critical as they define the boundaries of the areas previously described. 
a)

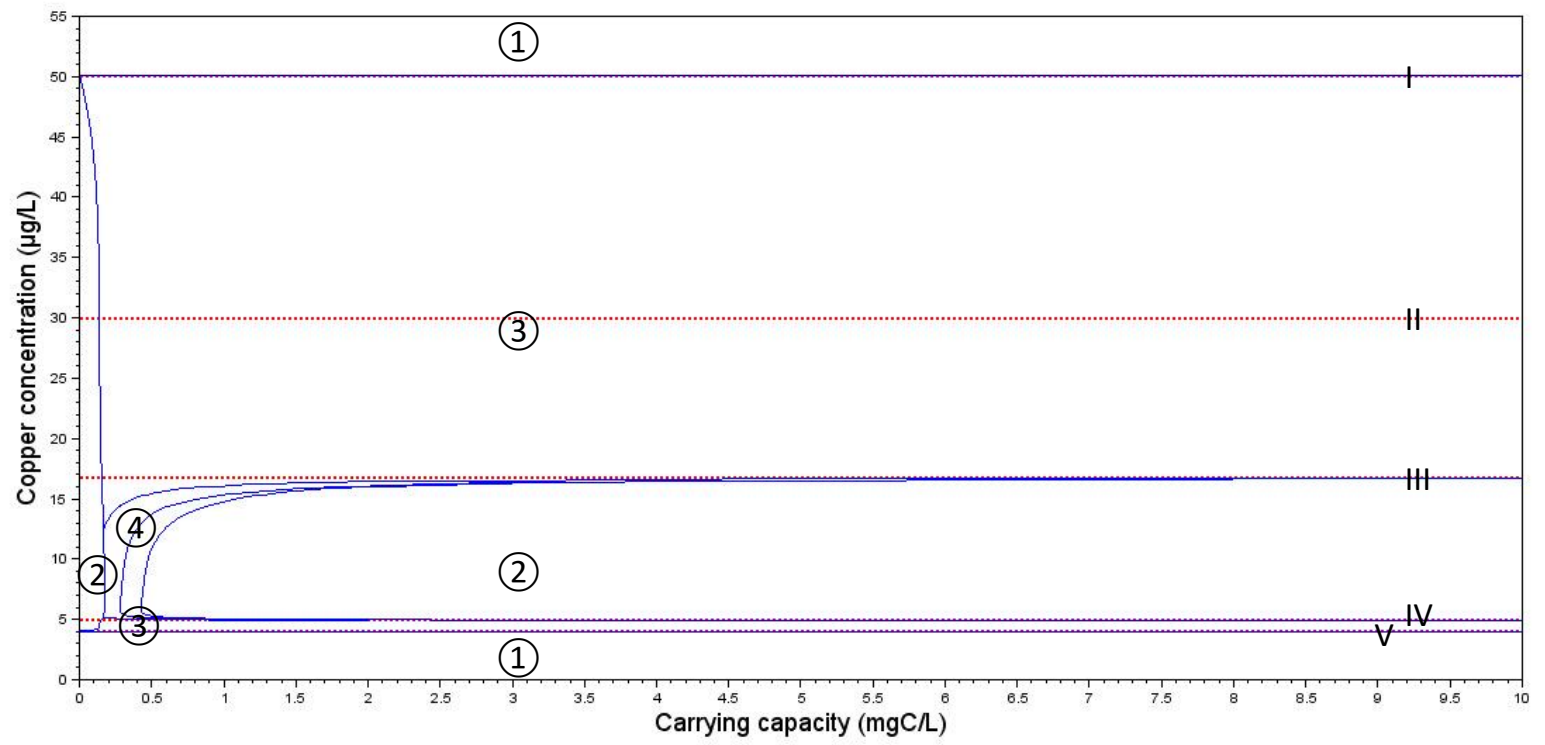

b)

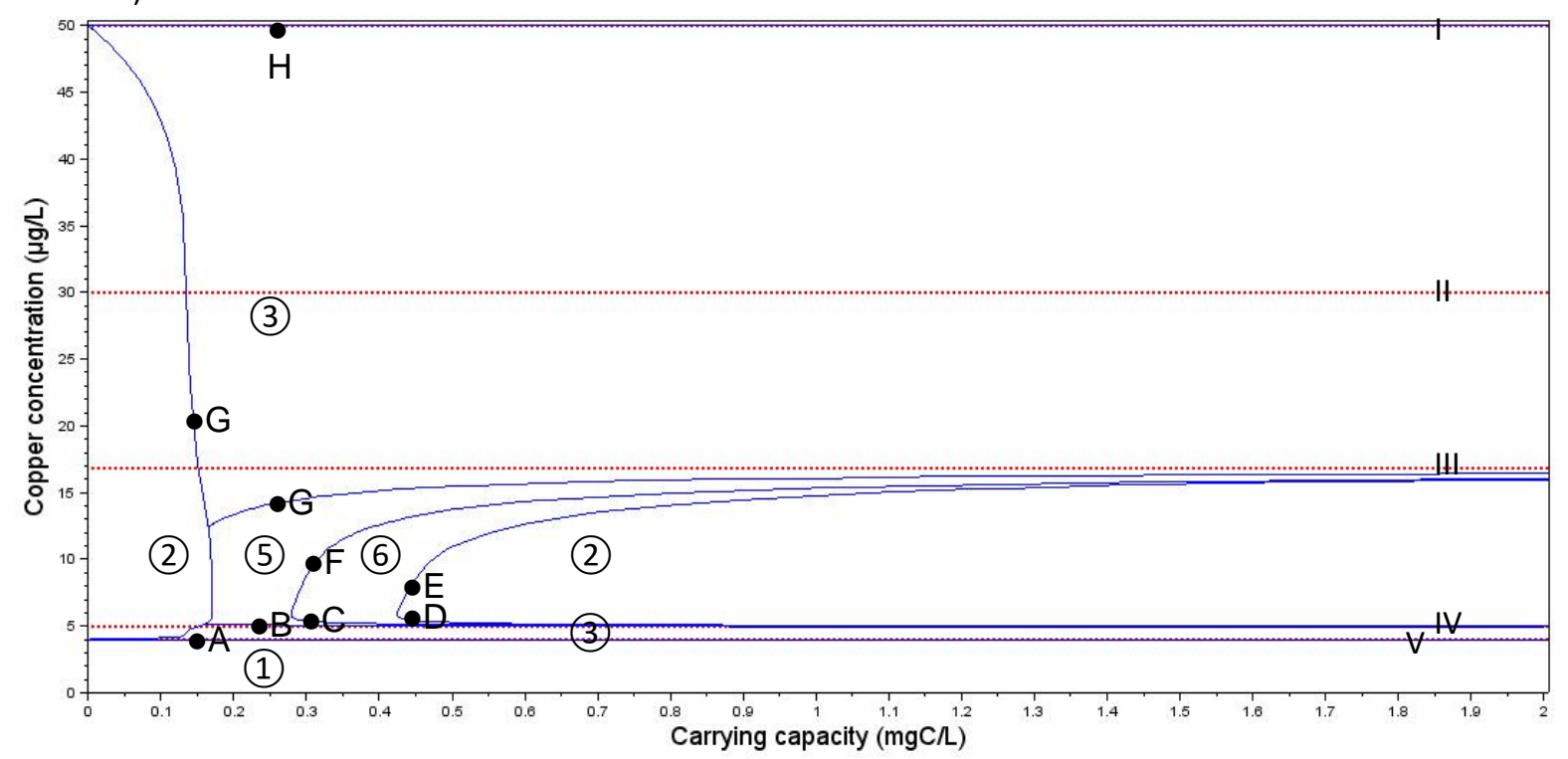

Figure 4: The different states of the model as a function of copper concentration $(\mu \mathrm{Cu} / \mathrm{L})$ and carrying capacity (mgC/L). a) Copper concentrations between 0 and $60 \mu \mathrm{gu} / \mathrm{L}$ and carrying capacity between 0 and $10 \mathrm{mgC} / \mathrm{L}$; b) Copper concentration between 0 and $51 \mu \mathrm{g} \mathrm{Cu} / \mathrm{L}$ and carrying capacity between 0 and $2 \mathrm{mgC} / \mathrm{L}$. Horizontal dotted lines show the toxicological values used in the model (from top to bottom, I: toxicity algae-EC 50, II: Daphnia-LD $_{50}$, III: toxicity Daphnia-EC ${ }_{50}$, IV: deficiency Daphnia-EC ${ }_{50}$, V: deficiency algae-LD $D_{50}$ ) For the areas with numbers in circles, see text for explanations. Dots with letters identify the threshold of copper concentrations between states.

Note that copper and nutrient enrichment interact and may promote the stable coexistence of Scenedesmus and Daphnia. For instance, for $\mathrm{K}=0.4 \mathrm{mgC} . \mathrm{L}^{-1}$, with an increasing copper concentration from 4 to $16 \mu \mathrm{g} \mathrm{Cu} . \mathrm{L}^{-1}$, the model outputs are Scenedesmus alone, population oscillations, stable coexistence, and again Scenedesmus alone (Figure 4b, areas 3, 6, 5 and 3). Population oscillations are due to a high productivity, while increasing copper concentration stabilizes the system before the extinction of the consumer. The interaction between copper 
pollution and nutrient enrichment also promotes the persistence of Daphnia for a limited range of copper concentration and carrying capacity. For instance, for $\mathrm{K}=0.7 \mathrm{mgC} . \mathrm{L}^{-1}$, with an increasing copper concentration from 4 to $16 \mu \mathrm{g} \mathrm{Cu} . \mathrm{L}^{-1}$, the model predicts the persistence of Scenedesmus alone first because of a Daphnia copper deficiency (area 3) and then a Daphnia exclusion driven by medium richness (area 2), followed by population oscillations (area 6), stable coexistence (area 5), and again Scenedesmus alone because of Daphnia copper toxicity (area 3).

\subsection{Sensitivity analysis}

Our model predicts different equilibrium states of the community. The boundaries of these states change with the copper concentration and carrying capacity (Figure 4), but also depend on other model parameters. Therefore, we conducted a sensitivity analysis to determine how these boundaries or threshold values between states depend on small changes in parameter values. To conduct this analysis, we changed parameter values by $-10 \%$ or $+10 \%$ and compared the threshold values of copper concentration between states to the initial threshold values. As the states' boundaries change with the medium richness, we assessed the threshold values for different carrying capacities. We identify the following eight threshold values (circles in Figure 4b): A) between no populations and Scenedesmus alone (areas 1 and 3); B) between Scenedesmus alone and stable coexistence (areas 3 and 5), or alternatively, for low carrying capacities, between Scenedesmus alone and no populations (areas 3 and 2); C) between stable and unstable coexistence (areas 5 and 6); D) between unstable coexistence and population extinction (areas 6 and 2); E) between population extinction and unstable coexistence (areas 2 and 6); F) between unstable and stable coexistence (areas 6 and 5); G) between stable coexistence and Scenedesmus alone (areas 5 and 3), or alternatively, for low carrying capacities, between no populations and Scenedesmus alone (areas 2 and 3); finally, 
H) between Scenedesmus alone and no populations (areas 3 and 1). The results are summarized in Figure S3.

The most influential parameters are the growth rate $r$ (maximal variation of $42.15 \%$ ), maximum intake rate $I_{\max }$ (maximal variation of $42.58 \%$ ) for a low carrying capacity $(\mathrm{K}=0.14 \mathrm{mgC} / \mathrm{L})$, and half-saturation constant $h$ (maximal variation of $19.18 \%$ ) and mortality rate $\mathrm{m}$ (maximal variation of $14.61 \%$ ) of Daphnia for high carrying capacity $(\mathrm{K}=0.5 \mathrm{mgC} / \mathrm{L})$.

The other parameters rarely have an impact above than their own variation (10\%). Interestingly, the parameters characterizing the shape of the Daphnia response to copper while taking into account the hormetic effects (parameters $d_{p}, b_{p}, v_{p}, s_{p}$, and $p_{m}$ in Figure S3 p-t) affect mostly the threshold values A-D and $\mathrm{H}$ (variation superior to 5\%). This effect is not found in the Scenedesmus response to copper: the parameters $d_{r}, b_{r}, v_{r}$, and $u_{r}$ do not have a strong effect on threshold values (Figure S3 i-1) and generally have less effect than Daphnia's parameters.

\section{Discussion}

\subsection{Effects of copper on Scenedesmus and Daphnia}

Our model shows that the Scenedesmus-Daphnia system obeys highly non-intuitive dynamics, with strong threshold effects and sudden population extinctions as the copper concentration increases or decreases in relation to the species' optimal range. Three types of outcomes are observed regarding population extinction and persistence. First, copper deficiency (less than $4 \mu \mathrm{g} . \mathrm{L}^{-1}$ ) precludes the growth of both species, while an increased copper concentration prevents Daphnia growth. Second, for an optimal range of copper concentration (between 5 and $16 \mu \mathrm{g} . \mathrm{L}^{-1}$ ), the model results show unstable and stable coexistence. Third, as copper concentration increases, toxic effects become apparent with the

extinction of Daphnia $\left(16 \mu \mathrm{g} . \mathrm{L}^{-1}\right)$ followed by Scenedesmus $\left(50 \mu \mathrm{g} . \mathrm{L}^{-1}\right)$. The different 
equilibriums reached by the Scenedesmus-Daphnia dynamics reveal the various noxious effects of copper. Low concentrations induce deficiency for either both species or Daphnia alone. High concentrations induce toxicity first on Daphnia and then on Scenedesmus. The threshold values are more sensitive to the parameters characterizing Daphnia's response to copper than Scenedesmus'. These threshold values of copper concentration also depend on the environment fertility. Nutrient enrichment is known to destabilize the Scenedesmus-Daphnia dynamics. Our results show that copper tends to counteract the negative effect of nutrient enrichment on the stability of the prey-predator system and even promotes Daphnia persistence for a limited range of copper concentration and carrying capacity.

\subsection{Copper and the stability of the prey-predator interaction}

In the area where the two species coexist (Figure 4), there are two zones: a stable zone where densities do not vary over time and an oscillating zone where densities present cyclic variations (Figure $4 \mathrm{~b}$, areas 5 and 6 , respectively). When carrying capacity increases, the system is destabilized and shifts from the stable to oscillating zone. This is the well-known paradox of enrichment (Rosenzweig, 1971; Appendix A). Conversely, for an algal carrying capacity exceeding $0.3 \mathrm{mgC} / \mathrm{L}$, when copper concentration increases, the system shifts from the oscillating to stable zone: thus, there is stabilization by copper. In addition, copper favors the persistence of Daphnia, which would otherwise become extinct because of a strong destabilization of the prey-predator dynamics, thus leading to the collapse of the predator population. Oscillations are caused by a high algal growth rate and a delay in the consumer numerical response caused by saturation of the predator captured by the type II functional response. The noxious effects of copper on both the prey and predator retard both algal growth and predation and stabilize the interaction. The stabilization of the ScenedesmusDaphnia interaction is also due to the improvement of algal growth conditions following the 
decline of predator efficiency induced by copper pollution. This stabilization counteracts the destabilization effect of nutrient enrichment described as the paradox of enrichment.

Although surprising, these results have already been described in other contexts. For instance, Abrams and Walters (1996) analyzed a prey-predator model in which the prey can switch between vulnerable and invulnerable states in different locations. Several mechanisms can generate such a situation. For instance, as a prey grows, it may become protected from predation by its large body size. Otherwise, a prey may move back and forth from locations with predators to locations without predators, or it may reduce its activity in the presence of predators, and hence, decrease its vulnerability to predation. Abrams and Walters' model showed a stabilization of the prey-predator interaction and an increase in prey equilibrium density. Copper bioconcentrated by Scenedesmus cells makes it toxic to Daphnia, which can be viewed as a form of invulnerability. Roy and Chattopadhyay (2007) studied the interaction between a toxic prey and its predator. Their model showed the same results (stabilization of the prey-predator interaction and increase in prey equilibrium density) in addition to an increase in the predator equilibrium density. Our model shows the same results, but differs from these models as copper toxicity affects the predator directly through bioconcentration and indirectly through biomagnification.

Consequently, an antagonistic effect exists between nutrient enrichment and copper, which explains the expansion of the coexistence zone along the carrying capacity axis (Figure 4). However, the beneficial effects revealed by our model may not apply to other systems. GarayNarváez et al. (2013) showed that pollutants have a destabilizing effect on more complex ecosystems.

These counterintuitive results reveal that antagonistic effects between pollutants can mask the noxious effects of these very pollutants in natural systems, which is a disturbing observation. 


\subsection{Copper pollution and threshold values}

Our model shows a succession of different threshold values, depending on copper toxicity values (Table 1) for copper concentrations and carrying capacities. As copper concentration increases and moves away from species' optimal value, in a medium of intermediate fertility (0.36 mgC.L $\left.{ }^{-1}\right)$, the system first switches from unstable to stable dynamics, then Daphnia becomes extinct, and finally Scenedesmus also becomes extinct. The corresponding threshold values are $11.8,15$, and $50 \mu \mathrm{g} . \mathrm{L}^{-1}$, respectively. If copper concentration decreases, the system switches from unstable dynamics to Daphnia extinction and then Scenedesmus extinction, with the corresponding threshold values of 5.6 and $4 \mu \mathrm{g} . \mathrm{L}^{-1}$. However, these threshold values are highly dependent on $\mathrm{LD}_{50}$ and $\mathrm{EC}_{50}$ values (see horizontal dotted lines in Figure 4), for which Daphnia is more sensitive to copper than is Scenedesmus, as confirmed by the sensitivity analysis. Our model predicts a reduction in the optimal range defined by these values and obtained for isolated individuals, especially for the predator. For instance, Daphnia becomes extinct for a concentration below $\mathrm{EC}_{50}\left(16.8 \mu \mathrm{g} \cdot \mathrm{L}^{-1}\right)$, with this threshold decreasing with the carrying capacity. As in Lampert's (1989) experiments, these results highlight that the toxic effects of contaminants may be strikingly different when assessed on individuals in isolation or in an entire community.

Furthermore, our results challenge the use of the no-observed-effect concentration (NOEC) and lowest-observed-effect concentration (LOEC) that define pollutant concentrations with no or low effects on individuals.

At the community or ecosystem scale, NOEC and LOEC consequently encounter two issues: (1) effects on populations' density Figure 3 - our model shows no single NOEC or LOEC since population densities vary with copper concentration and environmental conditions - and (2) effects on equilibrium states Figure 4 - in our model, we can define a NOEC for each equilibrium state. For instance, the model shows stable and unstable 
coexistence with and without copper, and we can define a NOEC for stable and unstable coexistence.

Muyssen and Janssen (2007) estimated the copper NOEC and LOEC for Daphnia juveniles to be $75 \mu \mathrm{g} . \mathrm{L}^{-1}$ and $90 \mu \mathrm{g} . \mathrm{L}^{-1}$, respectively. The NOEC and LOEC for Daphnia adults exceed $130 \mu \mathrm{g} . \mathrm{L}^{-1}$ (Muyssen et al., 2007). As the $\mathrm{EC}_{50}$, NOEC, and LOEC of Daphnia individuals alone are higher than the predicted copper concentration of Daphnia extinction in our model in which individuals interact with their prey, community interactions may have synergistic effects with pollutants. The interaction between ecological interactions and pollution could thus be assessed by estimating NOECs or LOECs at the community level. For instance, Roussel et al. (2007) estimated the NOEC and LOEC of primary producers in a lotic ecosystem submitted to copper pollution to be 5 or $4 \mu \mathrm{g} . \mathrm{L}^{-1}$ and 25 or $20 \mu \mathrm{g} . \mathrm{L}^{-1}$, respectively, while individual organisms were only affected significantly at copper concentrations of 25 and $75 \mu \mathrm{g} . \mathrm{L}^{-1}$. Our results, however, show that the community dynamics switches from unstable to stable before the extinction of herbivores. This qualitative change in community dynamics is not accounted for in the endpoint tests, whereas it could be seen as a warning signal.

\section{Conclusion}

The need for more realistic ecotoxicological approaches has been highlighted previously (Kramer et al., 2011). Our model of a simple freshwater prey-predator ecosystem shows that predators may be more affected by copper pollution when community interactions are taken into account than when analyzed alone. At the community level, our analyses show that depending on the nutrient status of the system, copper pollution may stabilize the preypredator interaction, although this stabilization leads to predator extinction if copper concentration increases further. Copper pollution and nutrient enrichment may have 
antagonistic effects for a limited range of variation of these two perturbations, which may result in misleading information on ecosystem health.

\section{Acknowledgments}

This work was financially supported by the ANR Pulse 2010 CEPL 01004. ML was supported by the TULIP Laboratory of Excellence (ANR-10-LABX-41). FDH, ML, and LP would like to thank Nicolas Labrune who developed a previous version of the model and the referees for their comments. LP is also grateful to Nicolas Delpierre for the asymmetric double-sigmoid equation. 


\section{References}

Abrams, P., Walters, C., 1996. Invulnerable prey and the paradox of enrichment. Ecology 77, 1125-1133.

ATSDR, 1990. Toxicological profile for copper. Agency for toxic substances and disease registry.

Baird, D.J., Barber, I., Bradley, M., Soares, A.M.V.M., Calow, P., 1991. A comparative study of genotype sensitivity to acute toxic stress using clones of Daphnia magna Strauss. Ecotoxicol. Environ. Saf. 21, 257-265.

Berlow, E.L., Navarrete, S.A., Briggs, C.J., Power, M.E., Menge, B.A., 1999. Quantifying variation in the strengths of species interactions. Ecology, 80(7), 2206-2224

Berlow, E.L., Neutel, A.M., Cohen, J.E., de Ruiter, P.C., Ebenman, B., Emmerson, M., Fox, J.W., Jansen, V.A.A., Jones, J.I., Kokkoris, G.D., Logofet, D.O., McKane, A.J., Montoya, J.M., Petchey, O., 2004. Interaction strengths in food webs: issues and opportunities. Journal of Animal Ecology, 73, 585-598

Briand, F., McCauley, E., 1978. Cybernetic mechanisms in lake plankton systems: How to control undesirable algae. Nature 273, 228-230.

Burns, C.W., 1968. The relationship between body size of filter-feeding Cladocera and the maximum size of particle ingested. Limnol. Oceanogr. 13, 675-678.

Bossuyt, B.T.A., Janssen, C.R., 2003. Acclimation of Daphnia magna to environmentally realistic copper concentrations. Comparative Biochemistry and Physiology, Part C 136, $253-264$.

Campfens, J., MacKay, D., 1997. Fugacity-based model of PCB bioaccumulation in complex aquatic food webs. Environ. Sci. Technol. 31, 577-583.

Clement, B., Zald, S., 2004. A new protocol to measure the effects of toxicants on daphnidalgae interactions. Chemosphere 55, 1429-1438. 
Clements, W.H., Cherry, D.S., Vanhassel, J.H., 1992. Assessment of the impact of heavymetals on benthic communities at the Clinch River (Virginia): Evaluation of an index of community sensitivity. Can. J Fish. Aquat. Sci. 49, 1686-1694.

De Schamphelaere, K.A., Janssen, C.R., 2002. A biotic ligand model predicting acute copper toxicity for Daphnia magna: The effects of calcium, magnesium, sodium, potassium, and pH. Environ. Sci. Technol. 36, 48-54.

Demott, W.R., 1982. Feeding selectivities and relative ingestion rates of Daphnia and Bosmina. Limnol. Oceanogr. 27, 518-527.

Dudgeon, D., Arthington, A., Gessner, M., Kawabata, Z., Knowler, D., Leveque, C., Naiman, R., Prieur-Richard, A., Soto, D., Stiassny, M., Sullivan, C., 2006. Freshwater biodiversity: Importance, threats, status and conservation challenges. Biological Reviews 81, 163-182.

Fargasova, A., Bumbalova, A., Havranek, E., 1999. Ecotoxicological effects and uptake of metals $\left(\mathrm{Cu}^{+}, \mathrm{Cu}^{2+}, \mathrm{Mn}^{2+}, \mathrm{Mo}^{6+}, \mathrm{Ni}^{2+}, \mathrm{V}^{5+}\right)$ in freshwater alga Scenedesmus quadricauda. Chemosphere 38, 1165-1173.

Fathi, A.A., El-Shahed, A.M., 2000. Response of tolerant and wild strains of Scenedesmus biguja to copper. Biologia Plantarum 43, 99-103.

Ferrando, M.D., Andreu, E., 1993. Feeding-behavior as an index of copper stress in DaphniaMagna and Brachionus-Calyciflorus. Pharmacology, Toxicology and Endocrinology 106, $327-331$.

Fleeger, J.W., Carman, K.R., Nisbet, R.M., 2003. Indirect effects of contaminants in aquatic ecosystems. The Science of the Total Environment 317, 207-233.

Garay-Narváez, L., Arim, M., Flores, J.D., Ramos-Jiliberto, R., 2013. The more polluted the environment, the more important biodiversity is for food web stability. Oikos 122, 12471253. 
Gerritsen, J., Strickler, J.R., 1977. Encounter probabilities and community structure in zooplankton: A mathematical model. J. Fish. Res. Board Can. 34, 73-82.

Gutierrez, M.F., Paggi, J.C., Gagneten, A.M., 2012. Microcrustaceans escape behavior as an early bioindicator of copper, chromium and endosulfan toxicity. Ecotoxicology 21, 428438.

Havens, K.E., 1994. Structural and functional-responses of a fresh-water plankton community to acute copper stress. Environmental Pollution 86, 259-266.

Ingersoll, C.G., Winner, R.W., 1982. Effect on Daphnia pulex (de Geer) of daily pulse exposures to copper or cadmium. Environmental Toxicology and Chemistry 1, 321-327.

Jørgensen S.V. (ed.), 2010. Ecotoxicology: A Derivative of Encyclopedia of Ecology. Elsevier/Academic Press, Boston.

Knops, M., Altenburger, R., Segner, H., 2001. Alterations of physiological energetics, growth and reproduction of Daphnia magna under toxicant stress. Aquat Toxicol 53, 79-90.

Koivisto, S., Ketola, M., Walls, M., 1992. Comparison of five cladoceran species in shortand long-term copper exposure. Hydrobiologia 248, 125-136.

Kramer, V.J., Etterson, M.A., Hecker, M., Cheryl, A.M., Roesijadi, G., Spade, D.J., Spromberg, J.A., Wang, M., Ankley G.T., 2011. Adverse outcome pathways and ecological risk assessment: bridging to population-level effects. Environmental Toxicology and Chemistry 30(1), 64-76.

Lampert, W., Fleckner, W., Pott, E., Schober, U., Störkel, K.-U., 1989. Herbicide effects on planktonic systems of different complexity. Hydrobiologia 188/189, 415-424.

Lebrun, J.D., Perret, M., Geffard A., Gourlet-Francé, C. 2012. Modelling copper bioaccumulation in Gammarus pulex and alterations of digestive metabolism. Ecotoxicology 21, 2022-2030. 
Luoma, S.N., Rainbow, P.S., 2005. Why is metal bioaccumulation so variable? Biodynamics as a unifying concept. Environ. Sci. Technol. 39(7), 1921-1931.

Lürling, M., Van Donk, E., 2000. Grazer-induced colony formation in Scenedesmus: Are there costs to being colonial? Oikos $88(1), 111-118$.

Manyin, T., Rowe, C.L., 2008. Modeling effects of cadmium on population growth of Palaemonetes pugio: Results of a full life cycle exposure. Aquat Toxicol 88, 111-120.

McCauley, E., Murdoch, W.W., 1987. Cyclic and stable populations: Plankton as paradigm. Am. Nat. 129, 97-121.

McCauley, E., Murdoch, W.W., Watson, S., 1988. Simple models and variation in plankton densities among lakes. Am. Nat. 132, 383-403.

McCauley, E., Nelson, W.A., Nisbet, R.M., 2008. Small-amplitude cycles emerge from stagestructured interactions in Daphnia-algal systems. Nature 455, 1240-1243.

Mertz, W., 1981. The essential trace elements. Science 213, 1332-1338.

Murdoch, W.W., Nisbet, R.M., McCauley, E., De Roos, A.M., Gurney, W.S.C., 1998. Plankton abundance and dynamics across nutrient levels: test of hypotheses. Ecology 79 (4), 1339-1356.

Muyssen, B.T.A., Janssen, C.R., 2007. Age and exposure duration as a factor influencing $\mathrm{Cu}$ and Zn toxicity toward Daphnia magna. Ecotoxicol. Environ. Saf. 68, 436-442.

Nisbet, R.M., McCauley, E., De Roos, A.M., Murdoch, W.W., Gurney, W.S.C., 1991. Population-dynamics and element recycling in an aquatic plant herbivore system. Theor Popul Biol 40, 125-147.

Nomkoko, E.T., Jackson, G.E., Nakani, B.S., 2003. Chemical speciation and biodistribution studies of copper (II) complexes of poly(amine)amide ligands. Inorganic Chemistry Communications 6, 335-338. 
Nriagu, J.O., 1979. The global copper cycle, in: Nriagu, J.O. (Ed.), Copper in the Environment. Part I: Ecological Cycling. John Wiley, pp. 1-17.

Paquin, P.R., Gorsuch, J.W., Apte, S., Batley, G.E., Bowles, K.C., Campbell, P.G.C., Delos, C.G., Di Toro, D.M., Dwyer, R.L., Galvez F., Gensemer, R.W., Goss, G.G., Hogstrand, C., Janssen, C.R., McGeer, J.C., Naddy, R.B., Playle, R.C., Santore, R.C., Schneider, U., Stubblefield, W.A., Wood, C.M. Wu, K.B., 2002. The biotic ligand model: A historical overview. Comparative Biochemistry and Physiology, Part C 133, 3-35.

Peña-Castro, J.M., Martínez-Jerónimo, F., Esparza-García, F., Cañizares-Villanueva, R.O., 2004. Phenotypic plasticity in Scenedesmus incrassatulus (Chlorophyceae) in response to heavy metals stress. Chemosphere 57, 1629-1636.

Porter, K.G., 1973. Selective grazing and differential digestion of algae by zooplankton. Nature 244, 179-180.

Porter, K.G., Gerritsen, J., Orcutt, J.D., 1982. The effect of food concentration on swimming patterns, feeding-behavior, ingestion, assimilation, and respiration by Daphnia. Limnol. Oceanogr. 27, 935-949.

Reynolds, C.S., 2011. Daphnia: Development of model organism in ecology and evolution. Freshwater Reviews 4(1), 85-87.

Rosenzweig, M.L., 1971. Paradox of enrichment: Destabilization of exploitation ecosystems in ecological time. Science 171, 385-387.

Rosenzweig, M.L., MacArthur, R.H., 1963. Graphical representation and stability conditions of predator-prey interactions. American Naturalist XCVII, 209-223.

Roussel, H., Ten-Hage, L., Joachim, S., Le Cohu, R., Gauthier, L., Bonzom, J.M., 2007. A long-term copper exposure on freshwater ecosystem using lotic mesocosms: Primary producer community responses. Aquat Toxicol 81, 168-182. 
Roy, S., Chattopadhyay, J., 2007. Enrichment and ecosystem stability: Effect of toxic food. Biosystems 90, 151-160.

Sala, O.E., Chapin, F.S., Armesto, J.J., Berlow, E., Bloomfield, J., Dirzo, R., Huber-Sanwald, E., Huenneke, L.F., Jackson, R.B., Kinzig, A., Leemans, R., Lodge, D.M., Mooney, H.A., Oesterheld, M., Poff, N.L., Sykes, M.T., Walker, B.H., Walker, M., Wall, D.H., 2000. Biodiversity: Global biodiversity scenarios for the year 2100. Science 287, 1770-1774.

Scharler, U.M., Hulot, F.D., Baird, D.J., Cross, W.F., Culp, J.M., Layman, C.A., Raffaelli, D., Vos, M., Winemiller, K.O., 2005. Central issues for aquatic food webs: from chemical cues to whole system responses, in: De Ruiter, P., Wolters, V., Moore, J. (Eds), Dynamic Food Webs: Multispecies Assemblages, Ecosystem Development, and Environmental Change. Elsevier, pp. 451-462.

Shurin, J.B., Gruner, D.S., Hillebrand, H., 2006. All wet or dried up? Real differences between aquatic and terrestrial food webs. Proc. R. Soc. B, 273, 1-9

Strauss, S.Y., 1991. Indirect effects in community ecology: Their definition, study and importance. Trends in Ecology and Evolution 6, 206-210.

Sullivan, B.K., Buskey, E., Miller D.C., Ritacco P.J., 1983. Effects of copper and cadmium on growth, swimming and predator avoidance in Eurytemora affinis (Copepoda). Marine Biology 77, 299-306.

Town, R., Filella, M., 2000. A comprehensive systematic compilation of complexation parameters reported for trace metals in natural waters. Aquat. Sci. 62, 252-295.

Traas, T.P., Janse, H.H., Aldenberg, T., Brock, T.C.M., 1998. A food web model for fate and direct and indirect effects of Dursban ${ }^{\circledR} 4 \mathrm{E}$ (active ingredient chlorpyrifos) in freshwater microcosms. Aquat Ecol 32, 179-190.

Trudel, M., Rasmussen, J.B., 2001. Predicting mercury concentration in fish using mass balance models. Ecol. App. 11, 517-529. 
Untersteiner, H., Kahapka, J.Kaiser, H., 2003. Behavioural response of the cladoceran Daphnia magna STRAUS to sublethal copper stress: Validation by image analysis. Aquat Toxicol 65, 435-442.

Van den Brink, P.J., Blake, N., Brock, T.C.M., Maltby, L., 2006. Predictive value of species sensitivity distributions for effects of herbicides in freshwater ecosystems. Human and Ecological Risk Assessment 12, 645-674.

Van Holthoon, F.L., Van Beek, T.A., Lürling, L., Van Donk, E., De Groot, A., 2003. Colony formation in Scenedesmus: A literature overview and further steps towards the chemical characterization of the Daphnia kairomone. Hydrobiologia 491, 241-254.

Van Veen, E., Burton, N., Comber, S.Gardner, M., 2002. Speciation of copper in sewage effluents and its toxicity to Daphnia magna. Environmental Toxicology and Chemistry 21, $275-280$.

Villeneuve, D.L., Garcia-Reyero, N., 2011. Vision \& strategy: Predictive ecotoxicology in the 21st century. Environmental Toxicology and Chemistry 30(1), 1-8.

WHO, 1998. Copper. Environmental health criteria. World Health Organization.

Winner, R.W., Farrell, M.P., 1976. Acute and chronic toxicity to four species of Daphnia. J. Fish. Res. Board Can. 33, 1685-1691.

Wu, X., Zhang, J., Quin, B., Cui, G., Yang, Z., 2013. Grazer density-dependent response of induced colony formation of Scenedesmus obliquus to grazing-associated infochemicals. Biochemical Systematics and Ecology 50, 286-292.

Yan, H., Pan, G., 2002. Toxicity and bioaccumulation of copper in three green microalgal species. Chemosphere 49, 471-476. 


\section{Appendix A}

Here, we detail the paradox of enrichment (Rosenzweig, 1971). First, Figure S1 presents the dynamics of Scenedesmus and Daphnia for three carrying capacities, 0.26, 0.36, and $0.56 \mathrm{mgC} . \mathrm{L}^{-1}$. We observe three types of dynamics corresponding to these carrying capacities: stable populations, oscillating populations, and extinction. Therefore, increasing medium richness destabilizes populations and may lead to their extinction. This destabilization caused by medium enrichment was described by Rosenzweig (1971) and termed the paradox of enrichment.

Final densities for carrying capacities ranging between 0 and $5 \mathrm{mgC} . \mathrm{L}^{-1}$ are summarized in Figure S2: when the carrying capacity is below $0.17 \mathrm{mgC.} \mathrm{L}^{-1}$, the medium cannot support populations. For carrying capacities allowing the persistence of both populations, we observe the three outputs previously described. First, populations are stable; for a carrying capacity above $0.284 \mathrm{mgC} . \mathrm{L}^{-1}$, the system is unstable and oscillation amplitudes increase with carrying capacity; finally, oscillations with wide amplitude cause the extinction of populations. During an uncertain phase from 0.429 to $0.454 \mathrm{mgC} . \mathrm{L}^{-1}$, algae alone can survive when oscillations cause Daphnia's extinction. 


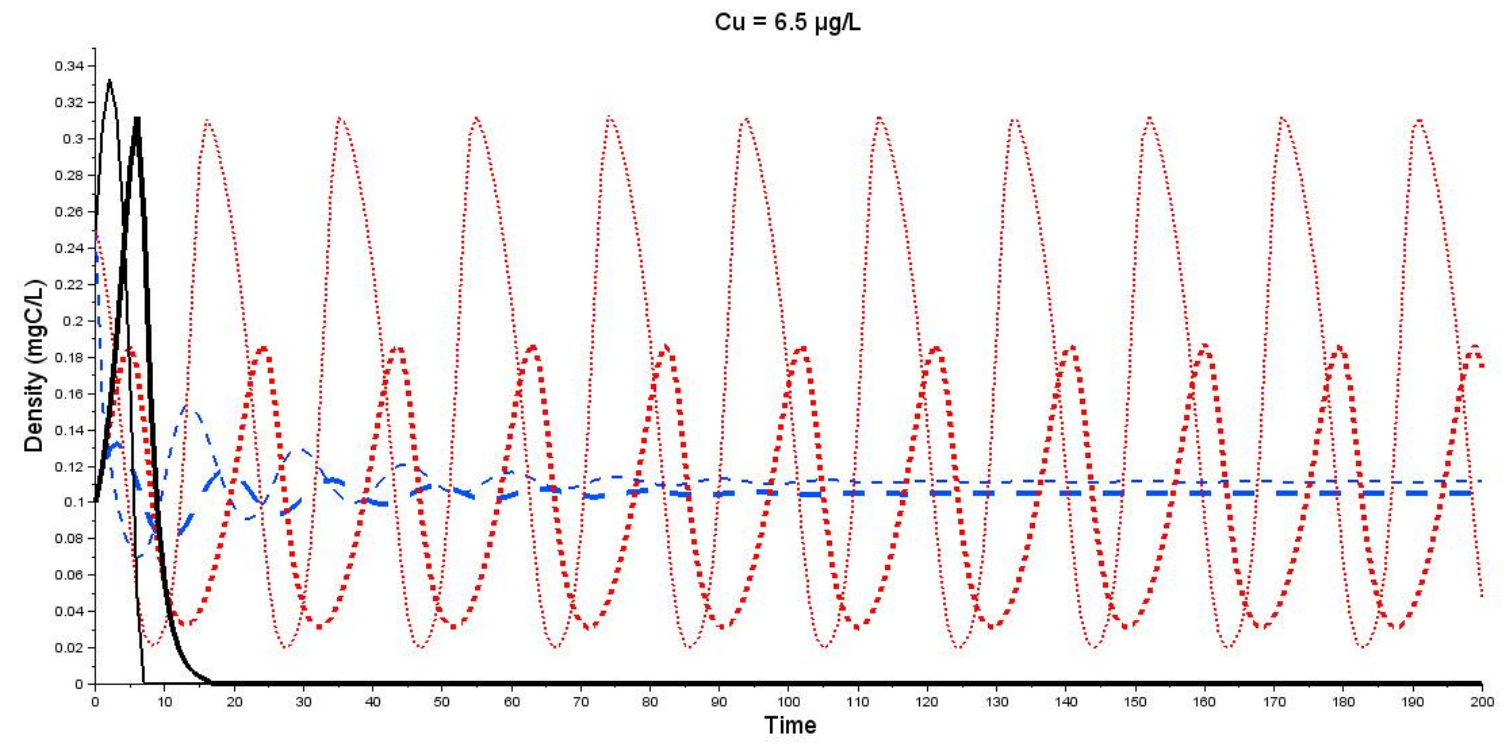

Figure S1: Scenedesmus (thin lines) and Daphnia (bold lines) dynamics for three values of carrying capacity: 0.26 (dashes), 0.36 (dotted lines), and 0.56 (solid lines) $\mathrm{mgC} / \mathrm{L}$ with a copper concentration of $6.5 \mu \mathrm{g} / \mathrm{L}$.

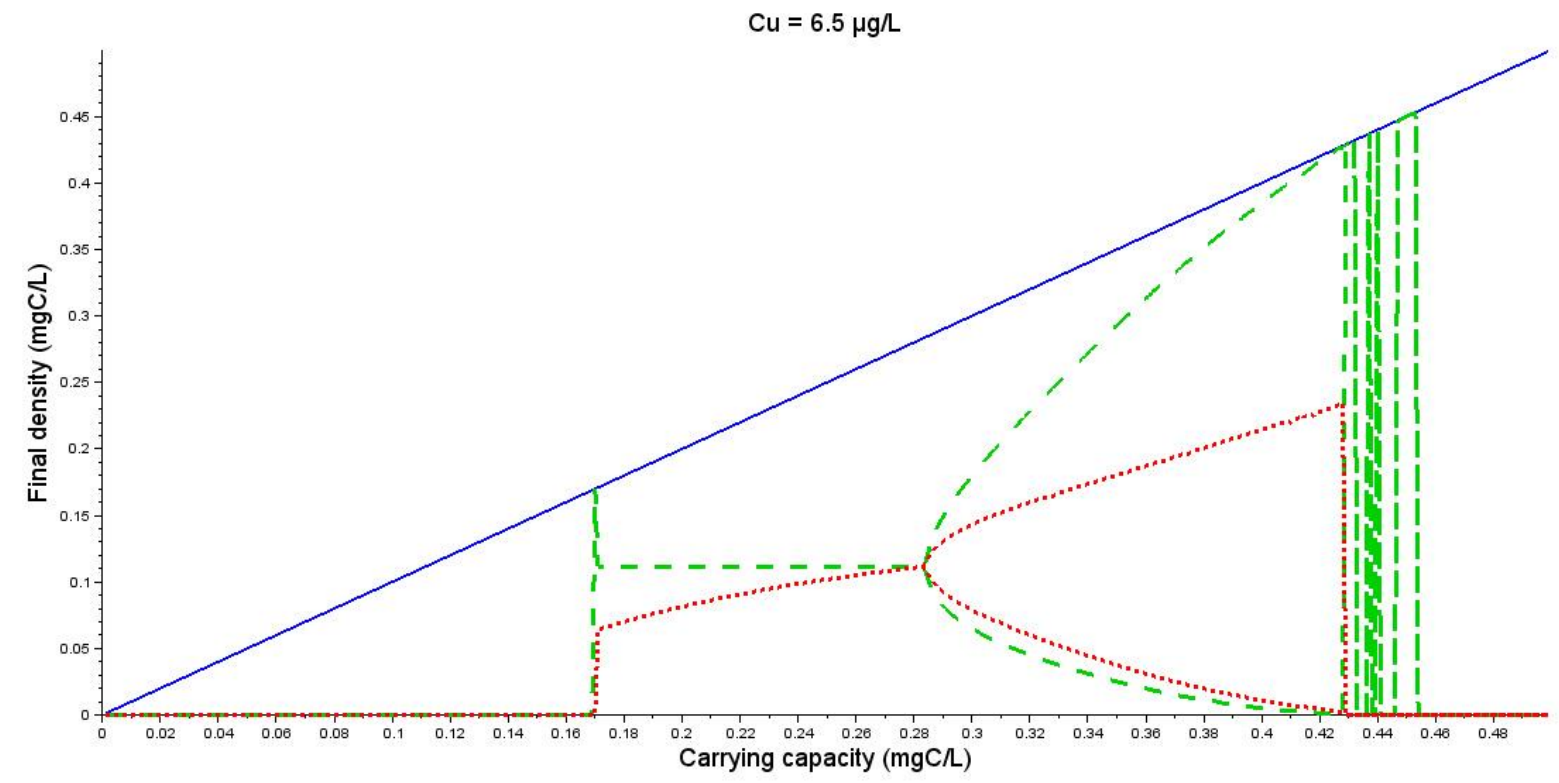

Figure S2: Scenedesmus (dashes) and Daphnia (dot lines) final densities for carrying capacities ranging between 0 and $0.5 \mathrm{mgC} / \mathrm{L}$. Solid line: Scenedesmus carrying capacity. Between 0.284 and $0.429 \mathrm{mgC} / \mathrm{L}$, the two lines per population correspond to the oscillations minima and maxima. 


\section{Appendix B}

Figure S3: Threshold variations in percentage of copper concentration when parameters vary by $\mathbf{- 1 0 \%}$ (left side of panels) or $+10 \%$ (right side of panels) for different carrying capacities (open circle: $\mathrm{K}=\mathbf{0 . 1 4} \mathrm{mgC} / \mathrm{L}$; full circle: $\mathrm{K}=0.26 \mathrm{mgC} / \mathrm{L}$; open square: $\mathrm{K}=0.36 \mathrm{mgC} / \mathrm{L}$; full square: $\mathrm{K}=0.5 \mathrm{mgC} / \mathrm{L}$; star: $\mathrm{K}=2.0 \mathrm{mgC} / \mathrm{L})$. A-H: threshold values defined in the text and illustrated in Figure $4 \mathrm{~b}$.
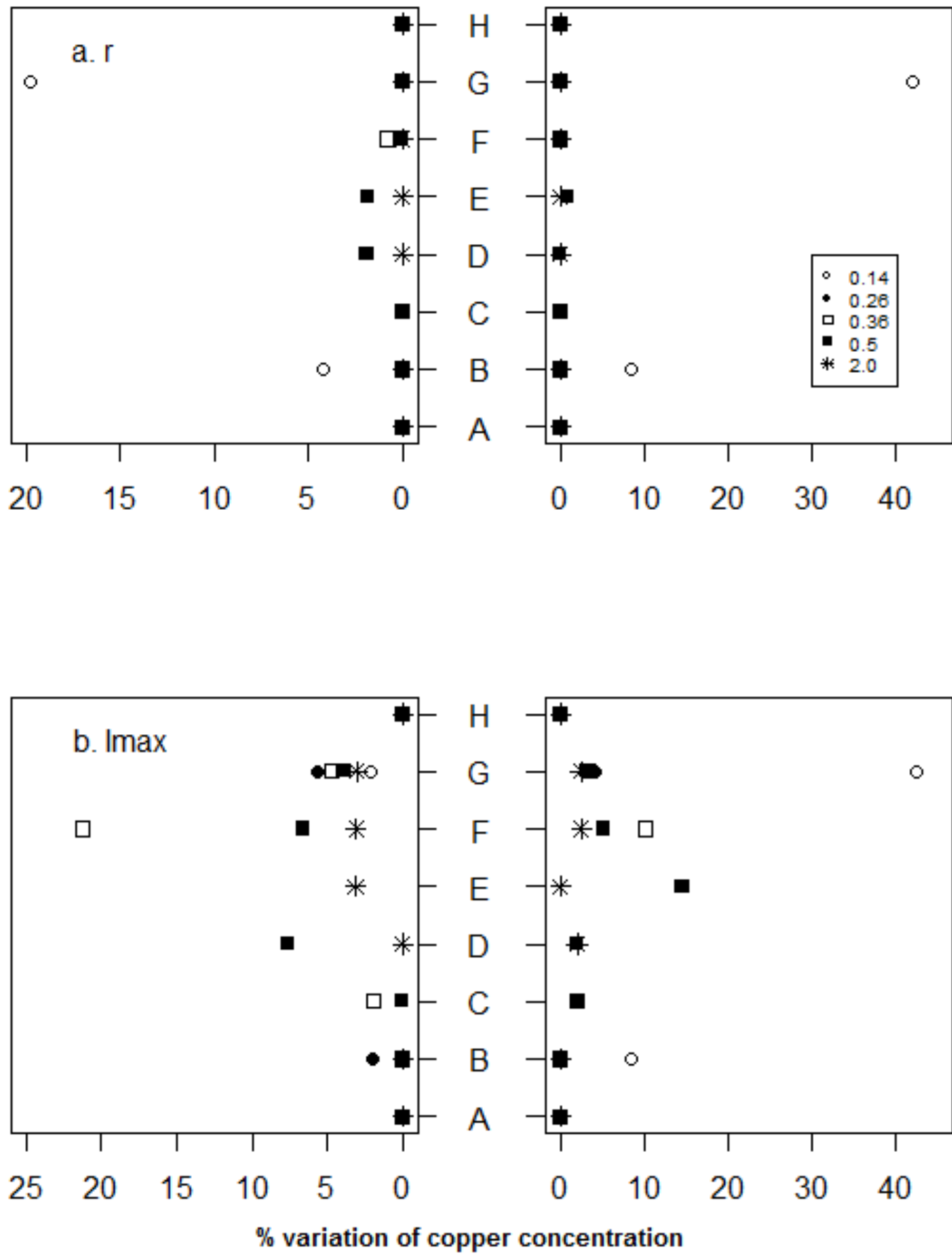

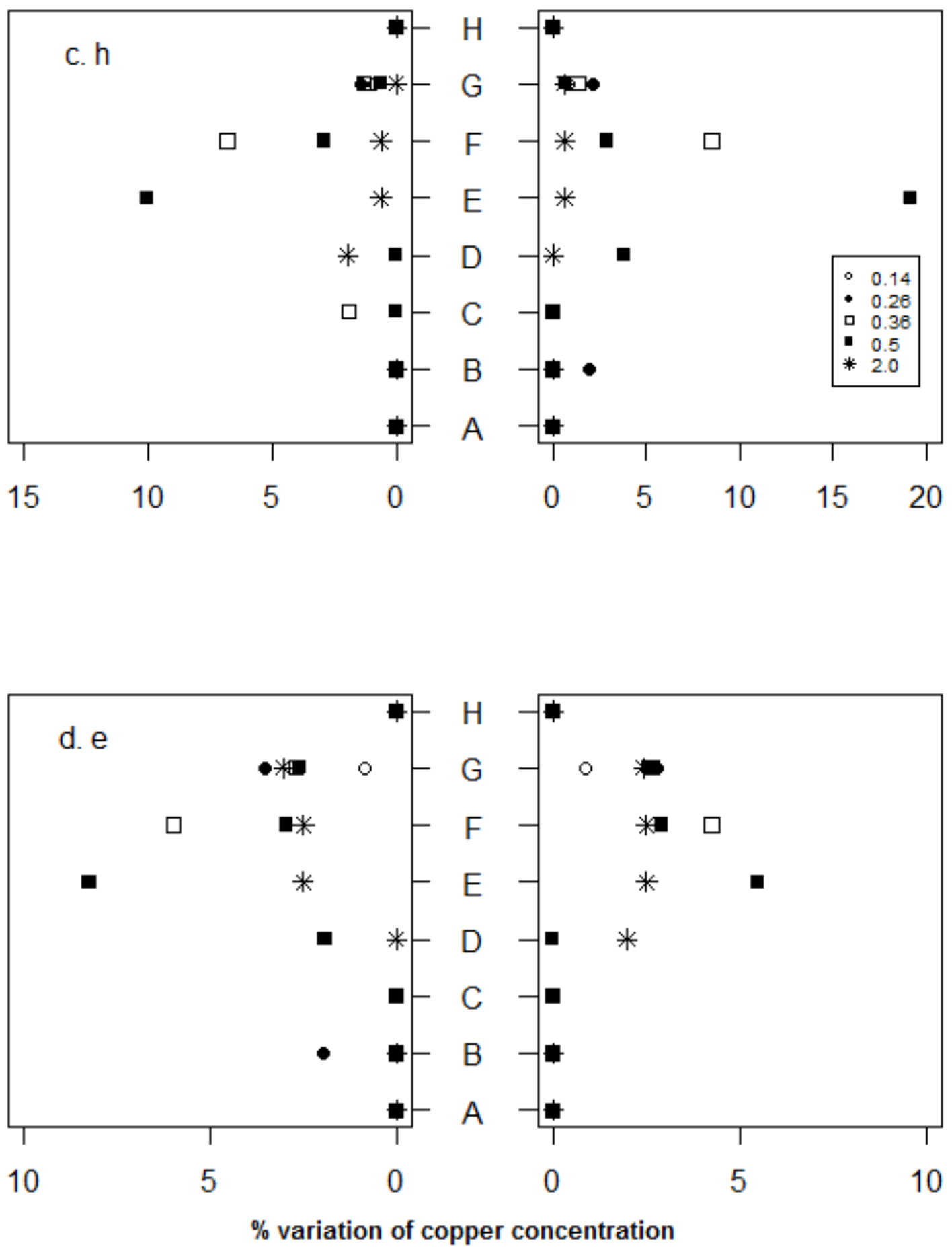

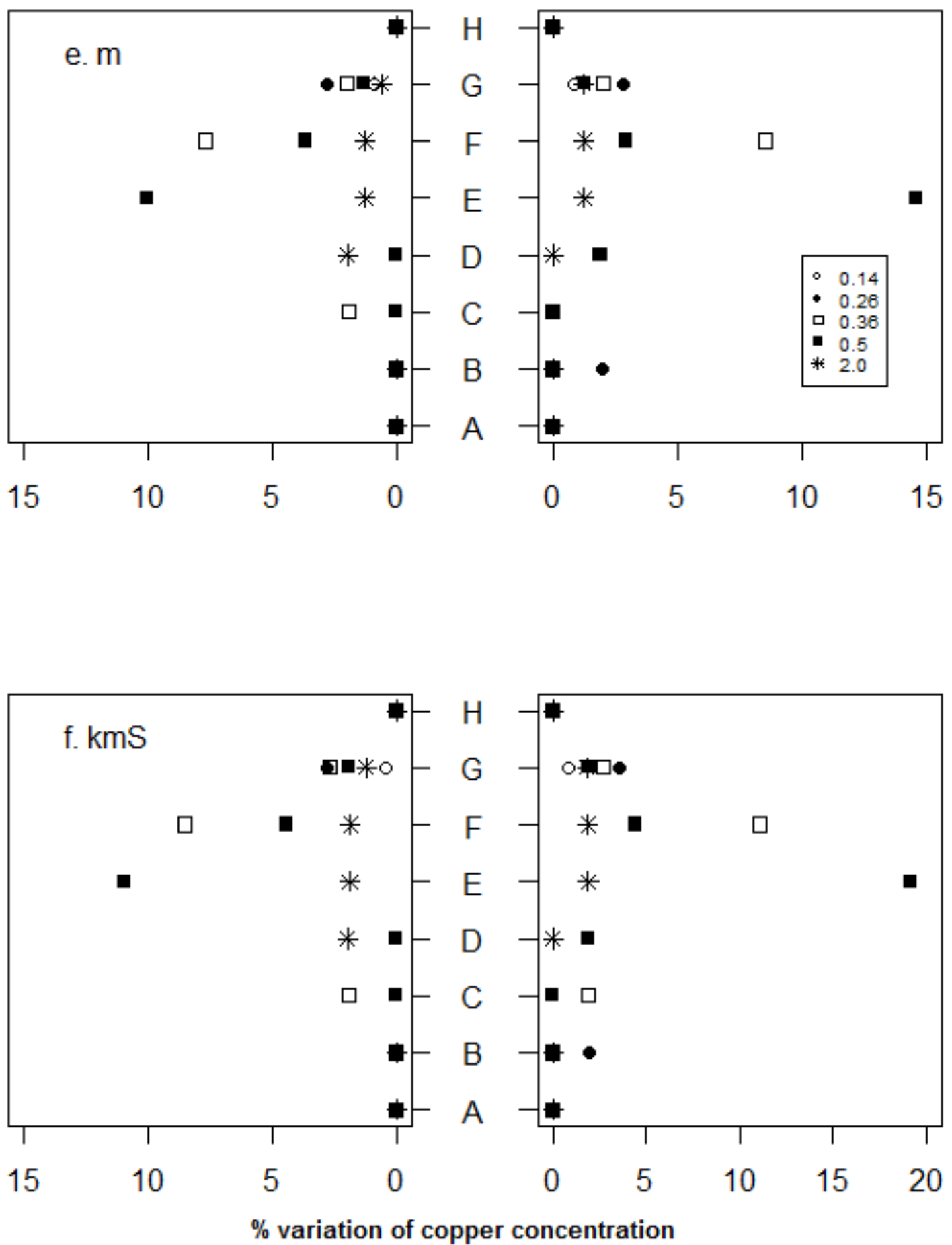

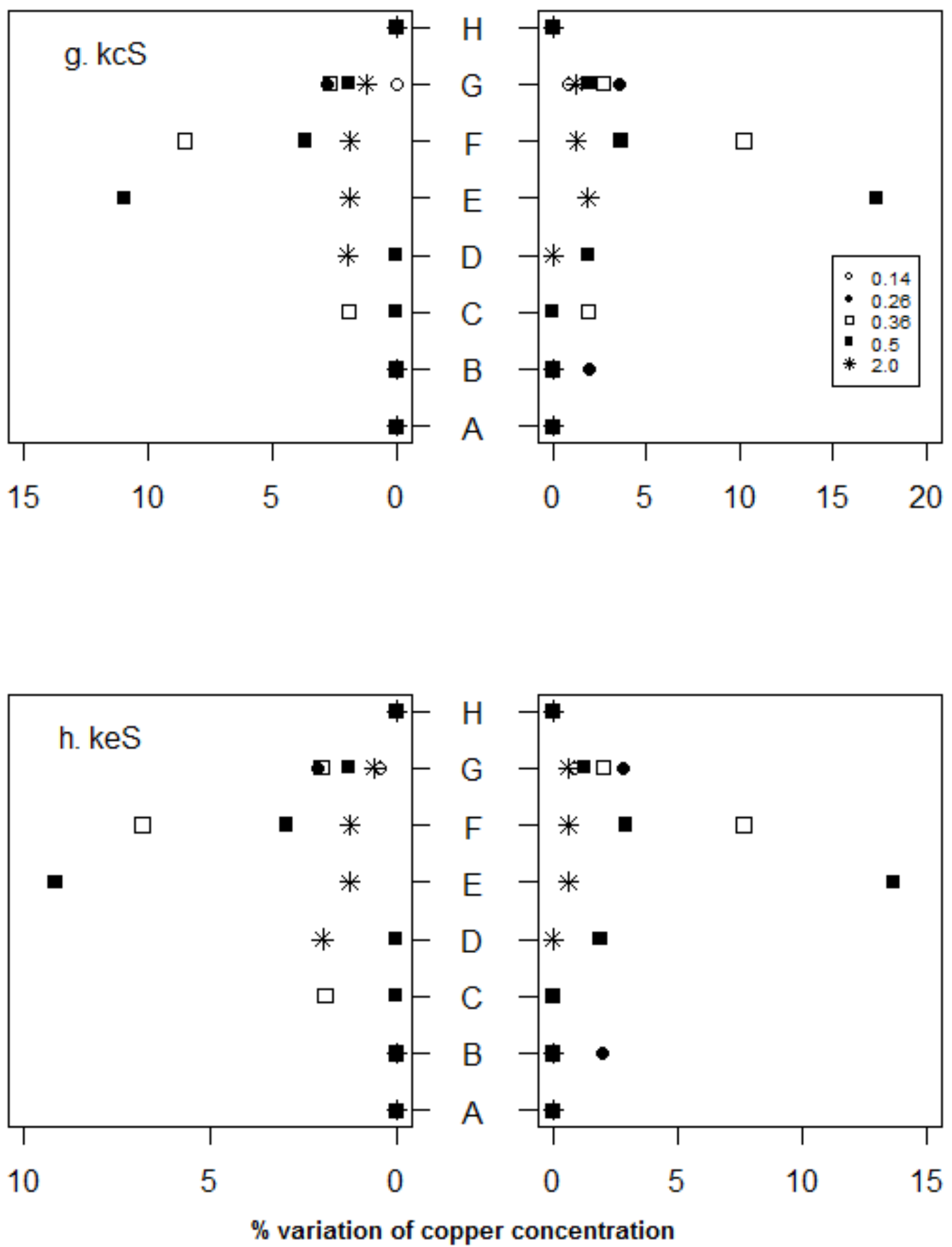

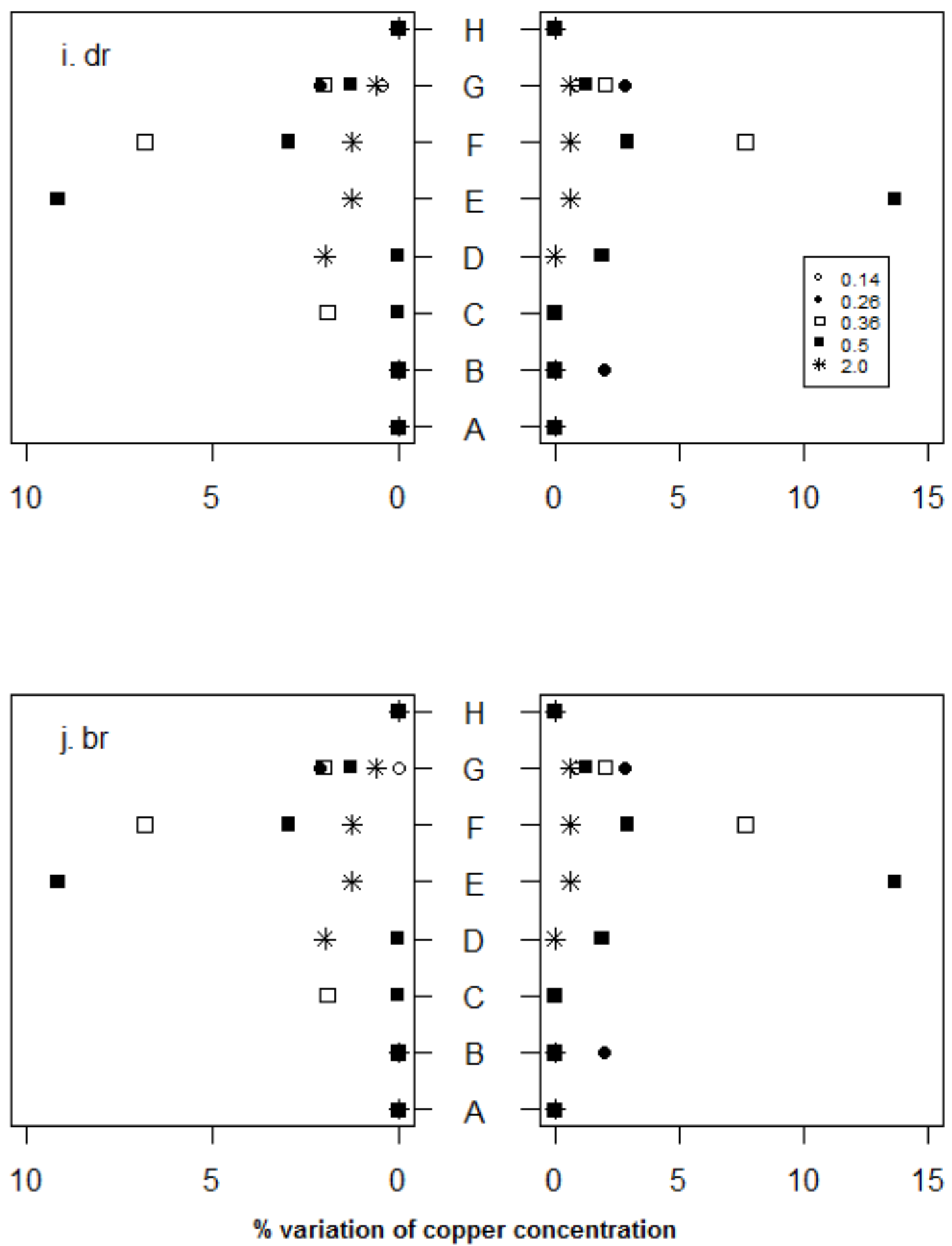

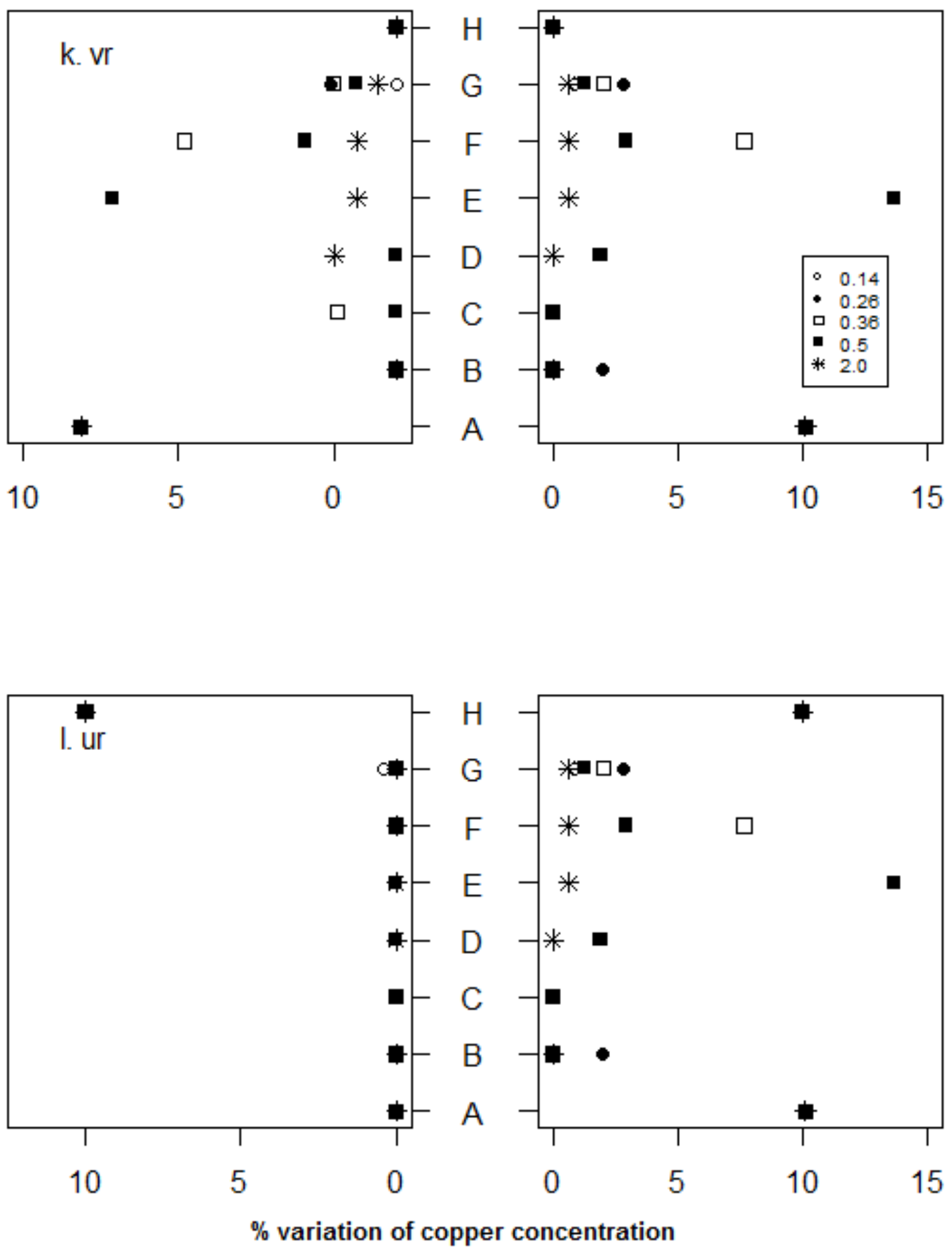

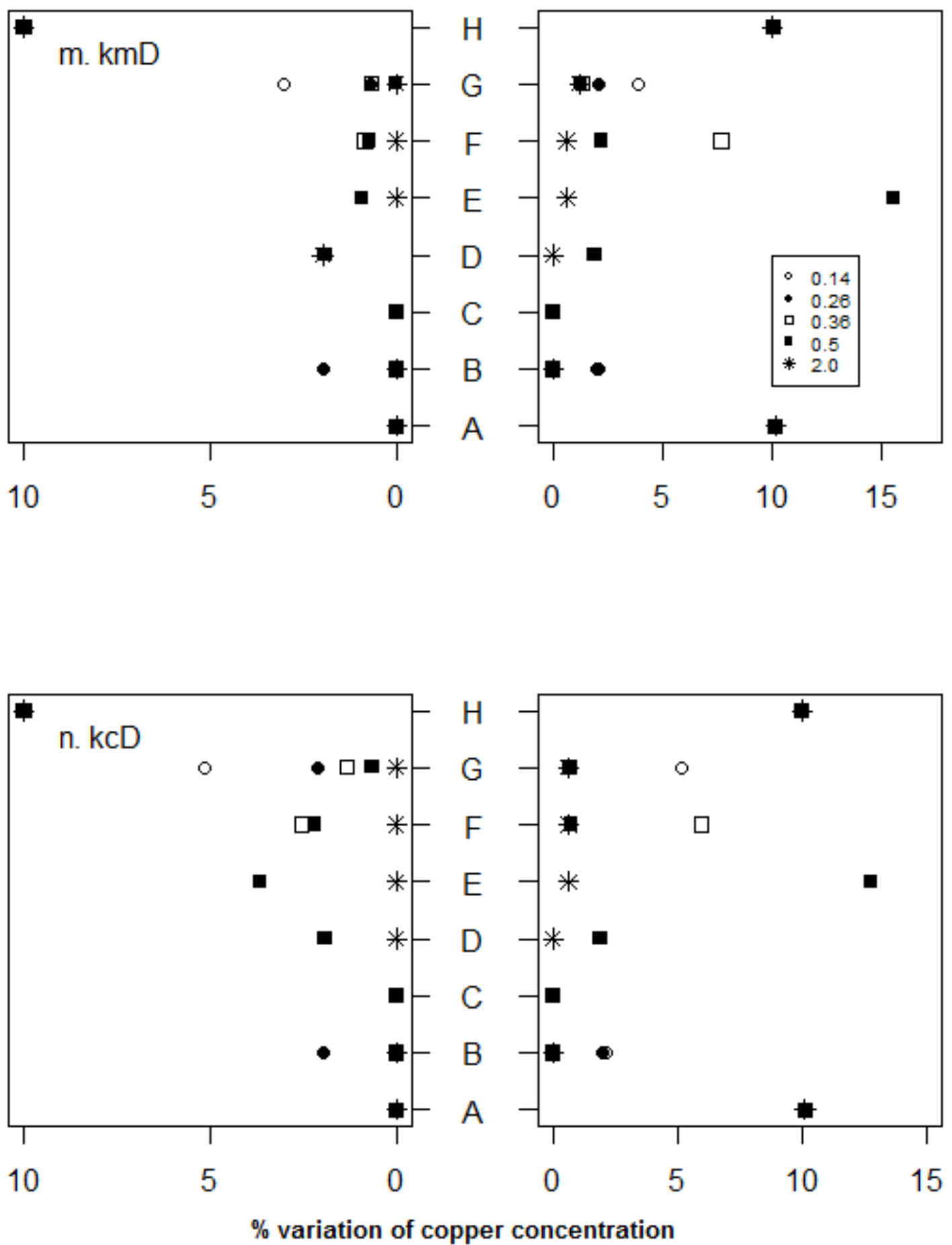

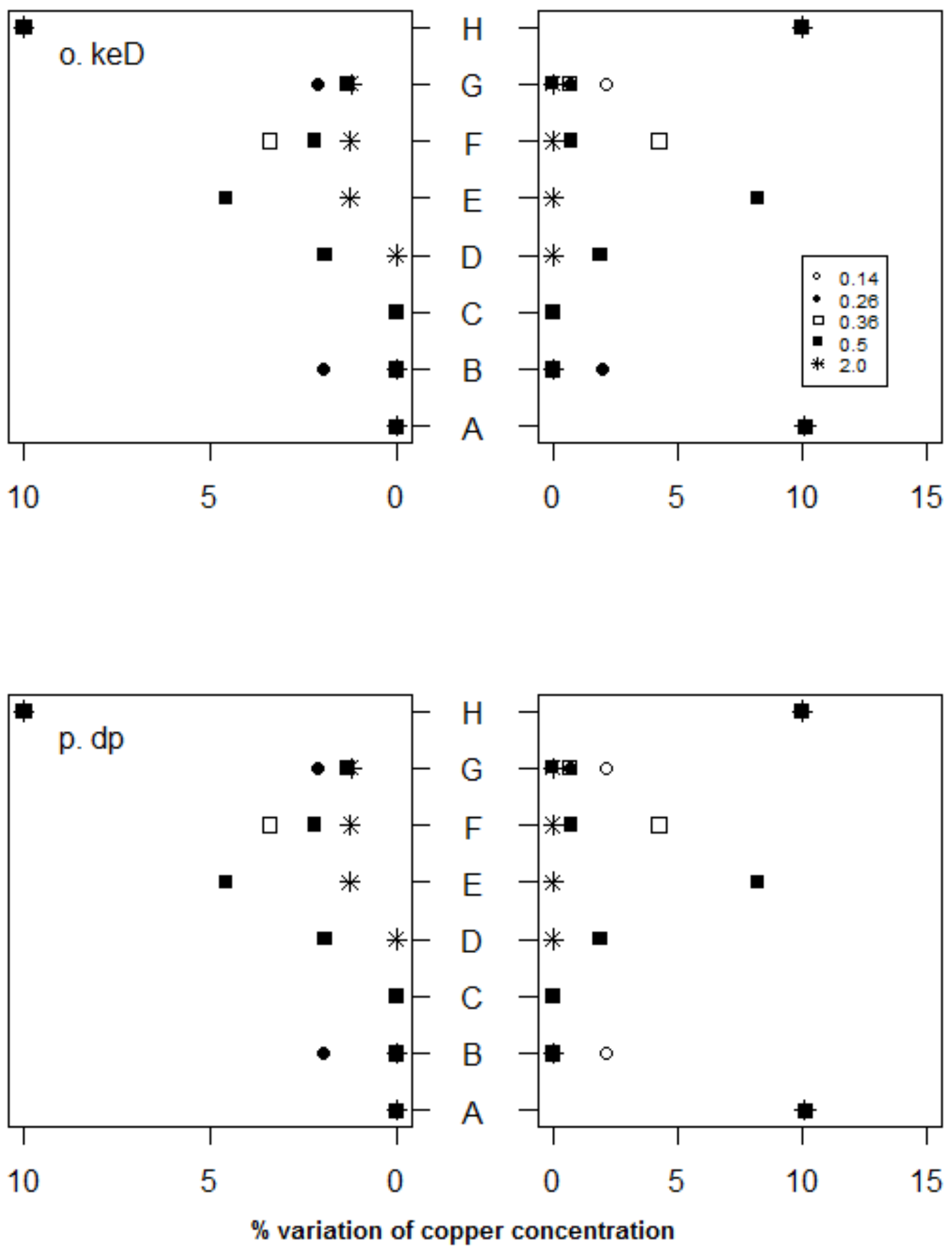

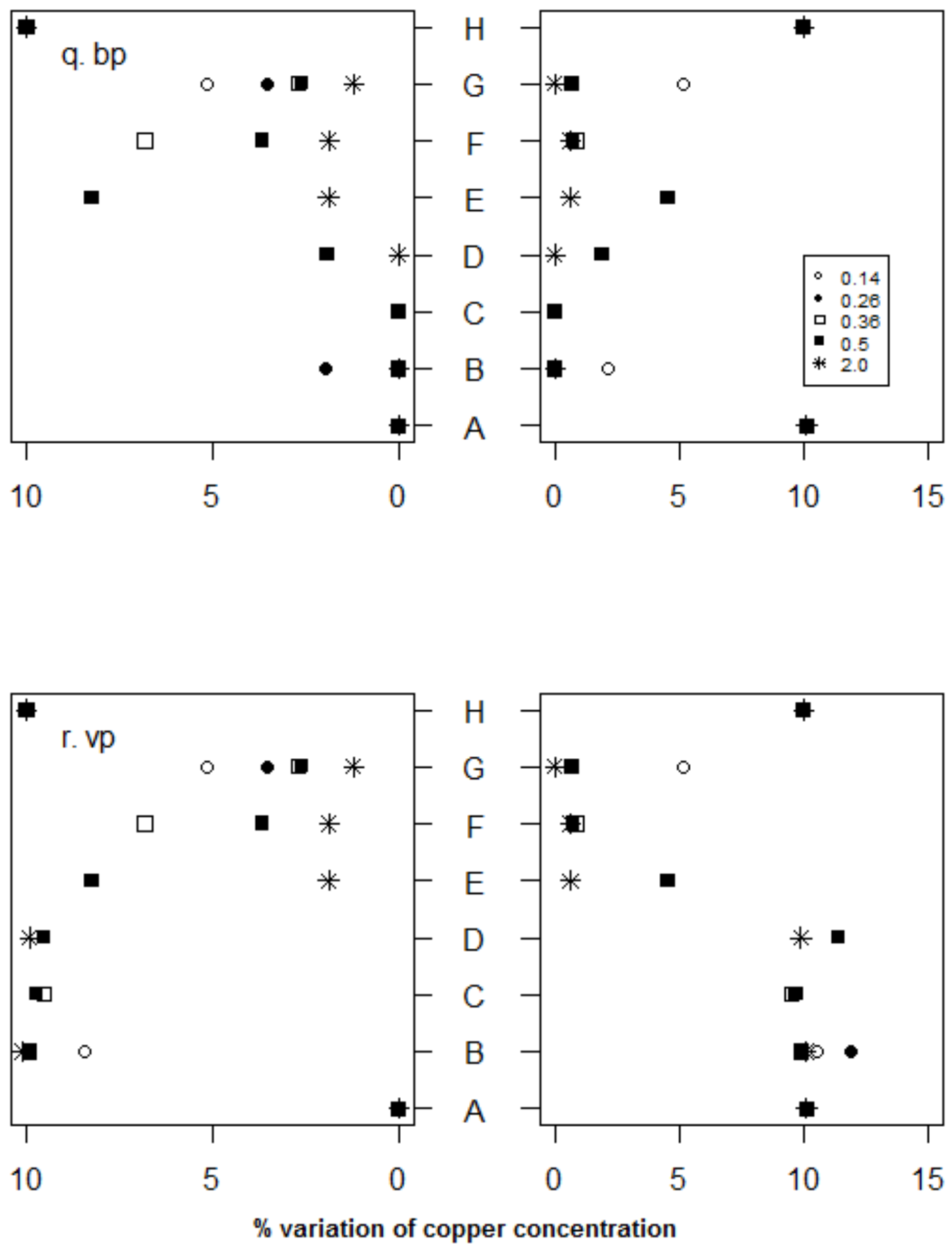

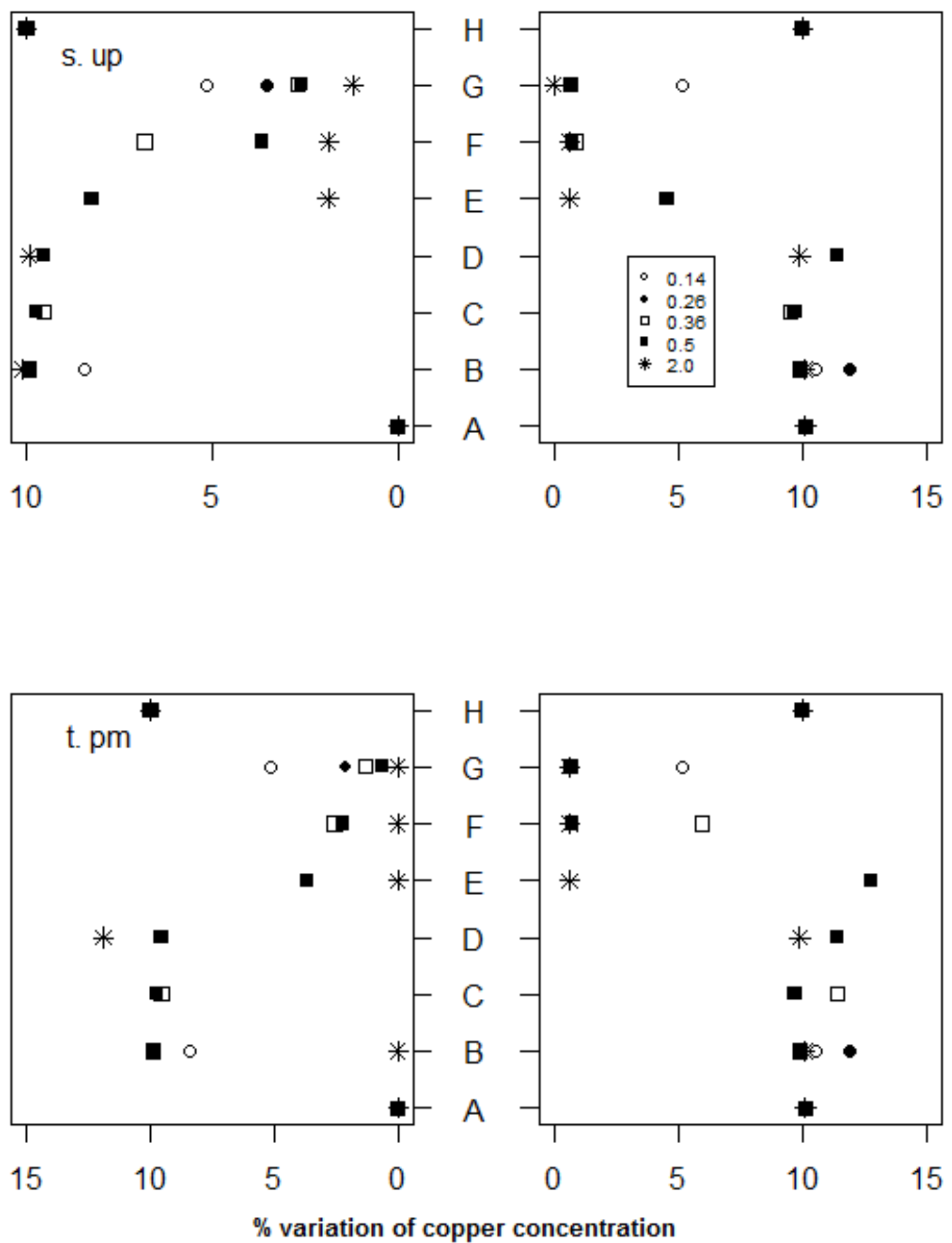